\title{
CRYSTAL PLASTICITY AND SUPERPLASTICITY IN QUARTZITE; A NATURAL EXAMPLE
}

\author{
J.H. BEHRMANN * \\ Department of Geology and Mineralogy, University of Oxford, Oxford OXI 3PR (United Kingdom)
}

(Received July 6, 1984; revised version accepted November 9, 1984)

\section{ABSTRACT}

Behrmann, J.H., 1985. Crystal plasticity and superplasticity in quartzite; a natural example. Tectonophvsics, $115: 101-129$.

Plastically deformed quartzites from the Betic Movement Zone (Betic Cordilleras. Spain) exhibit microstructures indicative of crystal plasticity on a mineral grain scale. Quartzites with dynamically recrystallized grain sizes larger than $10 \mu \mathrm{m}$ have strong crystallographic preferred orientations, narrow grain boundaries, little creep damage, and an inverse proportionality of dislocation density and grain size. Mylonites with grain sizes smaller than $10 \mu \mathrm{m}$ have low crystallographic preferred orientations, wide grain boundaries (up to $1000 \AA$ ), abundant creep damage, and decreasing dislocation density with diminishing grain size. This is thought to reflect a clear-cut shift in deformational regimes from dislocation creep to superplastic flow at $10 \mu \mathrm{m}$ grain size. Superplasticity can he acquired by quartzites which suffer dynamic recrystallization to grain sizes smaller than $10 \mu \mathrm{m}$ during an initial dislocation creep stage. Dislocation motion is the major accomodating mechanism for strain incompatibilities that arise during grain-boundary sliding in the mylonites.

It seems reasonable to estimate flow stresses from unbound dislocation densities and dynamically recrystallized grain sizes in the tectonite specimens. In the mylonites, dynamically recrystallized grain size probably reflects the stress magnitude before the shift in deformational mechanisms, and an estimate for late stage stresses is provided by unbound dislocation densities. In both deformational regimes the flow strength appears to depend on the extent of dynamic recrystallization.

\section{INTRODUCTION}

Quartz is one of the commonest minerals in the earth's continental crust. An understanding of its steady state plastic deformation mechanics in polycrystalline aggregates may help to define the rheology of a large proportion of crustal rocks.

* Present address: Geologisches Institut, Universität Tübingen. Sigwartstr. 10, D-7400 Tübingen. WestGermany. 
A multitude of studies on quartzites deformed in the plastic regime both naturally and experimentally have reported distinct crystallographic preferred orientation (C.P.O.) patterns (e.g., Schmidt, 1925; Baker et al., 1969; Tullis et al., 1973; Bouchez, 1978; Schmid et al., 1981b). There is general agreement today that intracrystalline slip and consequently rotation of crystal planes during straining (Lister et al., 1978; Bouchez et al., 1983) are the cause of such preferred orientations. Intracrystalline slip is achieved by motion of dislocations through the crystal lattice. Corresponding microstructural observations confirm this by high dislocation densities and the presence of subgrains and recrystallization (e.g.. McLaren and Phakey, 1965; McLaren and Hobbs, 1972; Carreras et al., 1977; White, 1976; McCormick. 1977).

Dislocation creep therefore appears to be a reasonable mechanism for plastic flow of quartzites, except for a regime of comparatively low differential stresses. low temperatures $\left(-300^{\circ} \mathrm{C}\right)$ and high fluid pressures (Rutter, 1976), where deformation by solution transfer prevails (Durney, 1972; Gray, 1979).

One of the most remarkable processes accompanying dislocation creep is dynamic, or syntectonic recrystallization of the deforming mineral aggregate (White. 1973). This results in mosaics of subequant grains, usually considerably finer sized than the strained original grains they replace. Dynamic recrystallization has been recognized as a major cause of softening in crystal aggregates (Etheridge and Wilkie, 1979; Poirier, 1980; White et al., 1980), leading to increases in rates of deformation, or stress drops.

Etheridge and Wilkie (1979) suspected that in analogy to the behaviour of some metals and ceramics there could be a switch in deformational mechanisms in quartzite from dislocation creep to superplasticity (Ashby and Verall, 1973; Boullier and Gueguen, 1975; Edington et al., 1976) as a result of the grain refining processes. In superplastic deformation most of the strain in the crystal aggregate is achieved by grains sliding relative to each other. Minor shape changes the grains have to undergo when sliding past each other are accommodated by diffusional mass transfer or dislocation motion within the grains. The diagnostic microstructural and textural features are a stable and very fine grain size $(<10 \mu \mathrm{m})$, equiaxial grains, and a low degree of crystallographic preferred orientation.

To date, superplastic behaviour of quartzite has not been observed in laboratory creep tests. Furthermore there is no coherent evidence for superplastic deformation under natural conditions. In this paper I wish to present microstructural and C.P.O. evidence from a suite of naturally deformed quartzite specimens that points to a change from dislocation creep to superplasticity. I shall aim to elucidate the necessary conditions for such a switch in deformation mechanisms, to discuss how it may affect our understanding of flow localization within the earth's crust and to point out how it influences the extraction of palaeostress information from microstructures. 
The samples were collected from the Betic Movement Zone (B.M.Z.), in the Sierra Alhamilla, southern Spain (Platt and Vissers, 1980; Platt et al., 1984; Platt and Behrmann, in press). This is a major intracrustal shear zone within the Betic Zone, the internal metamorphic segment of the Betic Orogen of Alpine age (Egeler and Simon, 1969; Torres-Roldan, 1979). The B.M.Z. separates two nappe complexes with rocks of distinctly different palaeogeography and different Alpine tectonometamorphic histories (Torres-Roldan, 1979; Vissers, 1981; Platt, 1982).

In the Sierra Alhamilla the B.M.Z is a zone of heterogeneous ductile shear and retrograde metamorphism up to $400 \mathrm{~m}$ thick beneath the higher Betic Nappes. It principally involves amphibolite to upper greenschist grade micaschists, quartzofeldspathic gneisses, and an abundance of strongly deformed sedimentary quartzites. The main-phase deformation within the B.M.Z. is thought to be contemporaneous with the NNE directed emplacement of the Higher Betic Nappes over the Nevado-Filabride footwall rocks (Behrmann and Platt, 1982), and occurred under lowermost greenschist facies conditions in a temperature range of $250^{\circ}-400^{\circ} \mathrm{C}$ (Behrmann, 1982). The quartzites suffered isoclinal folding during this main phase, with the development of an axial plane foliation $\left(S_{s}\right)$ defined by nattened large pre-tectonic quartz grains, and a stretching lineation $\left(L_{\mathrm{s}}\right)$ sub-parallel to the mesoscopic fold axes (Fig. 1). $S_{\mathrm{s}}$ is oriented sub-parallel to the major thrust faults, and $L_{s}$ trends $N$ to NE. Deformation is partitioned into two mylonite zones (Cuillas and Fuentes thrusts) and synchronous tectonization of their wall rocks (Platt and Behrmann, in press). Both, foliation and lineation show transitional increases in intensity into the mylonite zones. For the sake of clarity the quartzites sampled from the mylonite zones themselves will be called "mylonites", and those from the deformed wall rocks will be termed "tectonites". A detailed documentation of

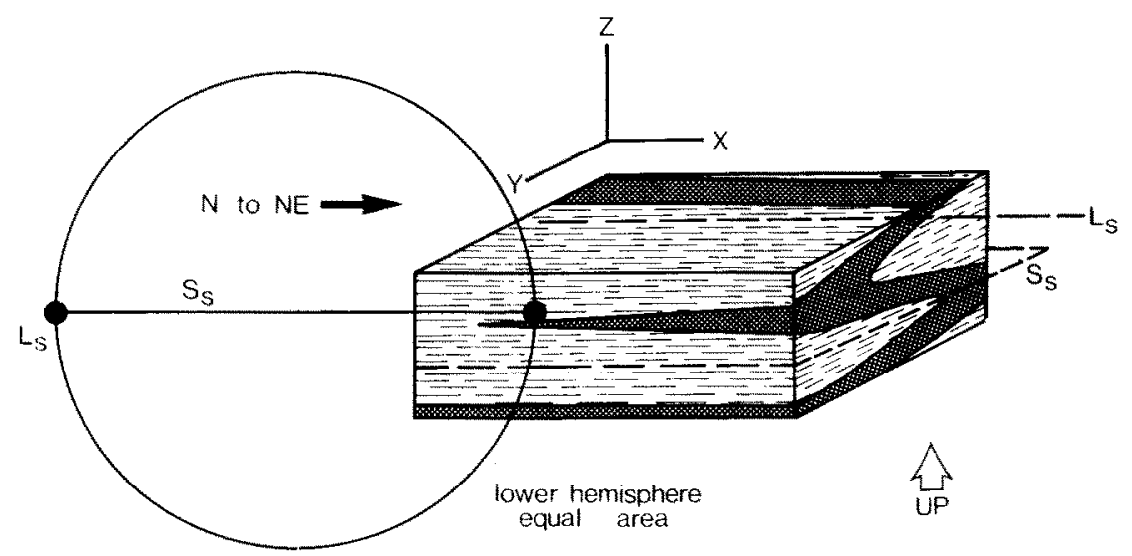

Fig. 1. Mesoscopic structural elements ( $L_{\mathrm{s}}, S_{\mathrm{s}}$, folded bedding), their geometrical relation to the finite strain reference frame $(X, Y, Z)$, and their relation to the quartz-c-axis and $X$-ray texture data. 

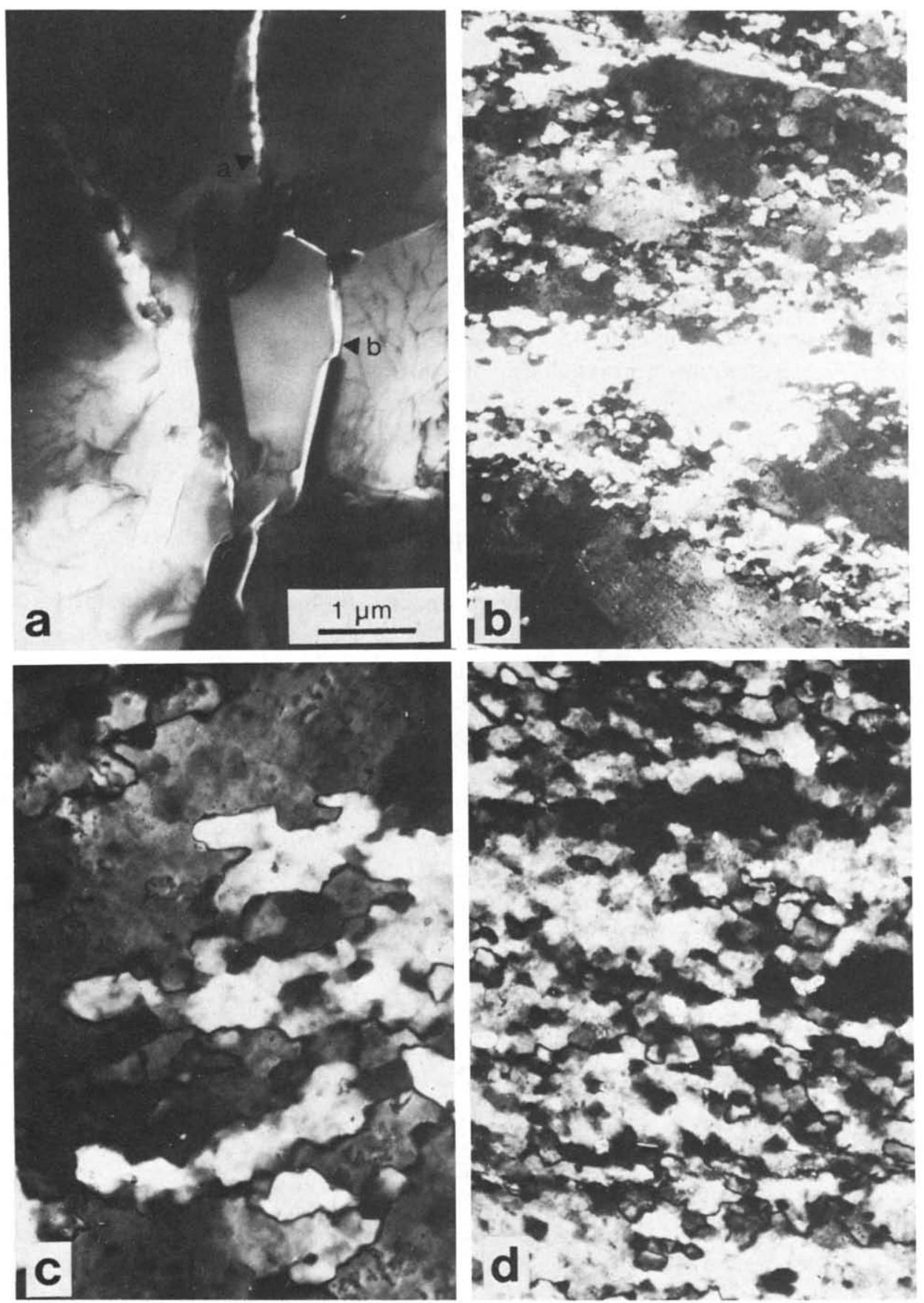

Fig. 2. a. Effects of specimen preparation on the thin foil: preferred etching along quartz-quartz grain boundary at (a) Mechanical fracture along grain boundaries frequently occurs when small layer silicate crystals are interspersed between quartz at (b). Bright field. 
structures and structural history of the B.M.Z. is to be found in Platt and Behrmann (in press), and an evaluation of finite deformation and palaeostress patterns is found in Behrmann (1984). The latter study demonstrates that the microstructures of the quartz tectonites are a product of steady state plastic flow. This in particular, and the clearcut geometrical relationship between mesoscopic and microscopic structures and major tectonic features, permits to regard tectonic activity in the B.M.Z. as a long-lasting and relatively well constrained deformation experiment that nature carried out on the quartzite tectonites and mylonites described in this paper.

\section{METHODS OF EXAMINATION}

Polarized light microscopes were used to collect basic microstructural observations and data. Grain diameters were determined by taking the averages of the long and short axes. A point counter operating on a squared grid was used to determine the impurity content of the specimens, and the percentage of recrystallized grains in the $X Z$ section (perpendicular to $S_{\mathrm{s}}$, parallel to $L_{\mathrm{s}}$ ).

Quartz $c$-axis orientations were analyzed with an optical universal stage using between 100 and 429 grains per specimen. Thin sections with $X Z$ orientations (Fig. 1) were surveyed on a squared grid. Analyses of the fine-grained mylonites were additionally based on data from $Y Z$ thin sections. X-ray C.P.O. data were measured on a computer controlled Seiffert-Scintag goniometer at E.T.H. Zürich, using Co $K \alpha$ radiation and operating in combined reflection and transmission modes (Siddans, 1976). The intensities of the diffracted beam were measured in a step scan mode with $5^{\circ}$ intervals in azimuth and tilt angles of a given specimen direction. The counting times for the two background positions on each small circle of constant tilt were 50 $\mathrm{sec}$, and $10 \mathrm{sec}$ for the other positions on the pole figure. The defocussing correction for the reflection mode is the same as used by Schmid et al. (1981a).

Transmission electron microscopy was carried out on JEM 100C and JEM 100CX machines, both fitted with STEM equipment, and the latter with an energy dispersive chemical microanalysis system. Both instruments operate with an accelerating voltage of $100 \mathrm{MV}$. For additional examinations of "thick" specimens a $1 \mathrm{kV}$ AEI microscope was used. Thin foils were produced from petrographic sections with $X Z$

b. Plastically deformed quartzite tectonite from the Castro slice (C5). Large grains show undulatory extinction and polygonal substructure. Dynamic recrystallization to $15 \mu \mathrm{m}$; new grains preferentially at large grain margins. $S_{\mathrm{s}}$ is defined by elongation of the large quartz grains and shape preferred alignment of white mica. $S_{\mathrm{s}}$ runs approximately E-W; section perpendicular to $S_{\mathrm{s}}$, parallel to $L_{\mathrm{s}}$; crossed polarizers; long side is $1 \mathrm{~mm}$.

c. Close up micrograph of a dynamically recrystallized portion of Fig. $3 \mathrm{~b}$. $S_{\mathrm{s}}$ runs E-W; crossed polarizers; long side is $250 \mu \mathrm{m}$. For explanation see text.

d. Detailed aspect of dynamically recrystallized quartz in Pt488. Crystallographic mismatch between grains is smaller than $30^{\circ}$ in many cases, so that most grain boundaries do not give marked image contrast. Interspersed calcite (bright specks). $X Z$-section; crossed polarizers; long side is $250 \mu \mathrm{m}$. 
and $Y Z$ orientations (Fig. 1). The thinning was achieved by $\mathrm{Ar}^{+}$bombardment according to the method described by Barber (1970).

Measurements of unbound dislocation densities $(\rho)$ were carried out by analogy to the method proposed by Ham (1961). The number of dislocations threading the area of the photographic frame was counted at large $(50 \mathrm{k}-100 \mathrm{k})$ magnifications, and then normalized to an unit area of $1 \mathrm{~cm}^{2}$. Up to 150 subareas were counted per foil, revealing large variations in the individual measurements. However, the average dislocation densities determined in six thin foils from specimen Pt 259 were very similar. To make all dislocations visible, irrespective of the diffracting condition and their orientation within the foil, irradiation damage (Cherns et al., 1980) was induced by exposing the counting area with a finely focussed beam for two or three seconds at $100 \mathrm{kEV}$. The beam was then defocussed and the stable dislocation line images were counted in situ. This method allows rapid analysis of many foil subareas and offers good practicability for dislocation densities lower than $3 \times 10^{9} \mathrm{~cm}^{-2}$ (Ham and Sharpe, 1961). To avoid low counts, very thin areas in the foils were neglected (Hirsch et al., 1967, p. 54). Unbound dislocation density $(\rho)$ is defined by the number per unit area of all lattice defects which are not incorporated into subgrain walls or dislocation tangles. Vacancy loops induced by electron irradiation were not counted. Effects of specimen preparation on thin foil are illustrated in Fig. 2a. I cannot say whether generation or rearrangement of dislocations happens during specimen preparation, but the generally brittle behaviour of quartz during handling in the laboratories would predict fracture rather than significant ductile deformation and hence modification of the dislocation substructure.

OPTICAL MICROSTRUCTURE

\section{Tectonites}

The most conspicuous microstructural feature is the bimodal distribution of grain size. The first group of grains has an average diameter greater than $200 \mu \mathrm{m}$ with strongly elongate shapes defining the pervasive $S_{\mathrm{s}}$ foliation. They usually show undulatory extinction, occasional deformation lamellae (Avé Lallemant and Carter, 1971), and often a well developed internal structure of more or less equant subgrains (Fig. 2b). The latter are characterized by a crystallographic mismatch of less than $10^{\circ}$. Their size is subject to considerable variation within single mineral grains, but in the vicinity of the grain margins they closely match the recrystallized grains in size and shape. The ellipsoidal outlines of these old grains are often modified by indenting zones of recrystallization, giving the grain boundaries a sutured appearance. The degrec of subgrain structure development strongly depends on the crystallographic orientation of the parent grain with respect to the external reference frame (Fig. 1). Grains with $c$-axis orientations close (less than $30^{\circ}$ ) to the foliation pole $(Z)$ display the most intense subgrain pattern. The intensity of the subgrain 
TABLE 1

Microstructural parameters

\begin{tabular}{|c|c|c|c|c|c|c|c|}
\hline \multirow{3}{*}{$\begin{array}{l}\text { Spec. } \\
\text { No. }\end{array}$} & \multirow{3}{*}{$\begin{array}{l}\text { Struct. } \\
\text { setting }\end{array}$} & \multicolumn{2}{|c|}{ Dyn. recryst. grain size } & \multicolumn{2}{|c|}{ Dyn. recrystallization (\%) } & \multirow{2}{*}{\multicolumn{2}{|c|}{$\begin{array}{l}\text { Unbound } \\
\text { dislocation density } \\
\left(\times 10^{8} \mathrm{~cm}^{-2}\right)\end{array}$}} \\
\hline & & \multirow[t]{2}{*}{$\begin{array}{l}\overline{\bar{d}} \\
(\mu \mathrm{m})\end{array}$} & \multirow{2}{*}{$\begin{array}{l}\bar{\sigma} \\
(\mu \mathrm{m})\end{array}$} & \multirow[t]{2}{*}{ uncorrected } & \multirow{2}{*}{$\begin{array}{l}\text { corrected } \\
\text { for pure } \\
\text { quartzite }\end{array}$} & & \\
\hline & & & & & & $\bar{\rho}$ & $\bar{\sigma}$ \\
\hline $\mathbf{P} 1200$ & CTS & 13.2 & 3.7 & 48.8 & 32.6 & 10.7 & 5.5 \\
\hline P1203 & CTS & - & - & 55.6 & 28.5 & - & - \\
\hline $\mathrm{P} 1207$ & CTS & 12.0 & 2.6 & 38.6 & 35.0 & 11.4 & 4.3 \\
\hline Pt211 & FMY & 6.5 & 0.9 & 99.6 & 79.9 & - & - \\
\hline $\mathrm{P} t 212$ & CTS & 14.1 & 4.0 & 47.9 & 42.0 & 11.0 & 7.2 \\
\hline $\mathbf{P t} 233$ & ALU & 52.0 & 14.7 & 89.5 & 85.2 & - & - \\
\hline $\mathrm{P} 1259$ & $\mathrm{CMY}^{*}$ & - & - & 94.1 & 66.5 & 7.1 & 4.7 \\
\hline Pt260 & $\mathrm{CMY}^{*}$ & 8.7 & 1.7 & 73.2 & 57.1 & 10.8 & 4.8 \\
\hline Pt458 & CMY & 10.3 & 2.0 & 98.3 & 54.1 & - & - \\
\hline P1460 & CMY* & - & - & 90.4 & 54.6 & - & - \\
\hline Pt463 & ALU & 19.8 & 4.5 & 53.4 & 52.3 & 5.3 & 3.6 \\
\hline Pt488I & $\mathrm{FMY}^{0}$ & 7.5 & 1.2 & 76.6 & 70.3 & 6.6 & 2.7 \\
\hline Pit488II & $\mathrm{FMY}^{0}$ & 6.9 & 1.0 & 97.2 & 74.6 & 3.9 & 2.8 \\
\hline Pt490 & CTS & 10.4 & 2.6 & 59.0 & 54.4 & 7.8 & 3.7 \\
\hline B2 & CTS & 23.1 & 6.0 & 68.5 & 53.6 & - & - \\
\hline B5 & ALU & 26.2 & 8.0 & 64.5 & 62.6 & 4.3 & 2.6 \\
\hline B29 & CTS & 18.7 & 4.3 & 77.1 & 58.4 & 7.6 & 3.6 \\
\hline B34 & ALU & 23.4 & 5.9 & 63.6 & 61.6 & 2.4 & 1.1 \\
\hline B44 & FMY & 6.7 & 1.0 & 87.1 & 67.1 & 3.0 & 2.2 \\
\hline B45 & FMY & 9.0 & 1.4 & 72.1 & 64.1 & 5.6 & 3.6 \\
\hline B47 & CTS & - & - & 64.0 & 47.8 & - & - \\
\hline B48 & ALU & 18.1 & 4.0 & 77.2 & 55.0 & 5.8 & 3.6 \\
\hline B49 & CTS & 11.6 & 2.2 & 79.2 & 35.4 & - & - \\
\hline B56 & ALU & 18.0 & 3.3 & 61.4 & 54.3 & 6.2 & 2.8 \\
\hline B57 & ALU & 26.2 & 9.7 & 81.7 & 53.6 & - & - \\
\hline B59 & ALU & 42.8 & 11.9 & 87.1 & 77.8 & -. & - \\
\hline $\mathrm{B} 60$ & ALU & 47.5 & 13.0 & 81.4 & 77.0 & - & - \\
\hline B68 & CTS & 12.6 & 2.2 & 35.4 & 20.6 & 12.6 & 6.5 \\
\hline B 69 & CTS & 12.3 & 2.7 & 34.4 & 32.2 & 11.4 & 5.0 \\
\hline B92 & FMY & 21.8 & 5.9 & 67.3 & 67.0 & - & - \\
\hline B101 & CTS & 13.6 & 2.0 & 57.9 & 54.2 & - & - \\
\hline B102 & CTS & 13.2 & 2.3 & 32.3 & 31.6 & 10.6 & 5.6 \\
\hline B103 & CTS & 12.9 & 2.5 & 72.1 & 36.7 & - & - \\
\hline B105 & $\mathrm{CTS}^{+}$ & 21.3 & 6.4 & 79.0 & 68.0 & - & - \\
\hline B106 & $\mathrm{CTS}^{+}$ & - & - & 76.3 & 60.7 & - & - \\
\hline $\mathrm{C} 1$ & & 5.0 & 1.0 & - & - & 1.6 & 1.4 \\
\hline $\mathrm{C} 5$ & CTS & 12.7 & 3.0 & 56.0 & 53.7 & 8.7 & 4.9 \\
\hline
\end{tabular}

Legend: ${ }^{*} ;{ }^{+}-$specimens taken from the same location; ${ }^{0}$ - different layers in the same specimen. CTS - Castro thrust slice; ALU - Alhamilla unit; FMY - Fuentes mylonite; CMY-Cuillas mylonite; $\bar{\rho} \quad$ standard deviation 
fabric decreases with diminishing angle between the respective $c$-axis and the intermediate axis of finite strain $(Y)$. In the $Y$ orientation the majority of the grains form extremely elongated ribbons with no visible subgrain structure. The large grains are interpreted as plastically deformed, but not dynamically recrystallized grains. Accordingly they can be used as markers to estimate the average finite $D_{s}$ strain (Behrmann, 1984) undergone by intracrystalline slip.

A variable proportion of the quartz is recrystallized to small $(10-50 \mu \mathrm{m})$ grains having a moderate elongation sub-parallel to the $S_{\mathrm{s}}$ foliation, constituting the second group of grains (Fig. 2b). Average aspect ratios are in the order of $X / Z=1.5$ to 1.7 . A close examination of the grain interiors (Fig. $2 \mathrm{c}$ ) in ultra thin sections shows that there are undulatory extinction and some polygonal substructures. Grain boundaries are straight or slightly curved. Microstructural patterns like this one are commonly interpreted as a result of dynamic, or syntectonic recrystallization (White, 1976). The recrystallized grain sizes were measured for a number of specimens (Table 1). The percentage of dynamically recrystallized grains in the $X Z$ sections was also determined along with the impurity content by point counting samples larger than 300 in 36 specimens (Table 1). Considerable variations appear in both recrystallized grain content and impurity. To obtain an objective estimate of dynamic recrystallization one has to find out in which way impurity content can modify recrystallization. For this purpose a banded, strongly heterogeneous quartz-mica mylonite was analyzed layer by layer. It shows a linear dependence between the percentage of recrystallized quartz $\left(q_{\mathrm{r}}\right)$ and impurity $(i)$ according to a function:

$q_{\mathrm{r}}=1.06 i+37.4$

With a correlation coefficient of 0.93 (Fig. 3). The approximate $45^{\circ}$ slope of the function indicates a one by one substitution of impurity and non-recrystallized quartz. Hence the data can be corrected for $100 \%$ pure quartzite $(i=0)$ with a

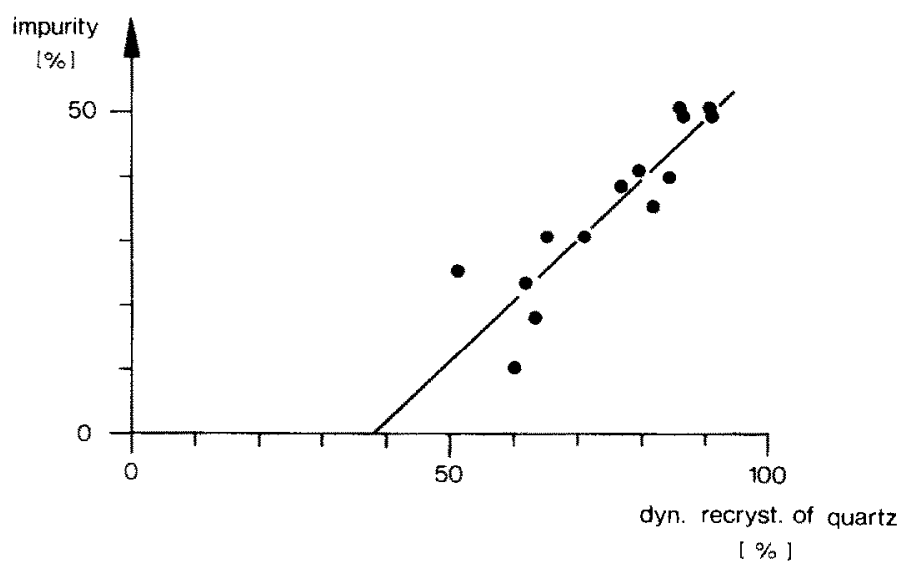

Fig. 3. Percentage of dynamic recrystallization in quartz as a function of impurity content. 
percentage of dynamic recrystallization $\left(q_{\mathrm{r}}^{\prime}\right)$ of:

$q_{\mathrm{r}}^{\prime}=\frac{n_{\mathrm{qr}}}{t} \times 100$

where $n_{\mathrm{qr}}$ is the number of recrystallized quartz grains counted and $t$ is the total number of points counted in a specimen (Table 1 ).

\section{Mylonites}

Quartzite specimens in the two mylonite carpets consist of a matrix of very fine $(7-10 \mu \mathrm{m}$ ) grains (see Fig. $2 \mathrm{~d}$ ). They are elongate with moderate $X / Z$ aspect ratios (smaller than 1.4). There is a notable gradation of grain sizes from the margins to the centres of the mylonite carpets. The finest-grained specimen (C1) of quartz mylonite (5 $\mu \mathrm{m}$ ) is associated with a narrow discrete shear zone at UTM location $561900 / 4092050$.

Intracrystalline features are very similar to the recrystallized tectonite grains. with undulatory extinction and polygonal cell structures in the larger recrystallized grains. Grain boundaries are straight or bent between triple points. Triple points are not usually in a $3 \times 120^{\circ}$ equilibrium. In impure specimens phengitic white mica flakelets or calcite crystals are occasionally interspersed among the quartz matrix at grain boundaries and triple junctions (Fig. 2d). There are a few large (>200 $\mu \mathrm{m}$ ) plastically deformed quartz crystals in the mylonite matrix with a well developed subgrain structure. The subgrain size is approximately identical to the matrix grain size, and marginal recrystallization of the large crystals suggests that the fine matrix aggregate was generated by progressive refining of originally coarse-grained quartzite. The intracrystalline features and the elongation of matrix grains parallel to $S_{\mathrm{s}}$ indicate that the latter microstructural evolution is a syntectonic one, i.e. contemporaneous with the formation of the mylonites themselves.

Table 1 gives the recrystallized grain sizes of the various mylonite specimens, and the percentage of recrystallization. Corrected for pure quartzite, the values are between 54 and $80 \%$.

\section{T.F.M. MICROSTRICTURE}

This paragraph concentrates on the quantitative aspects of quartz dislocation substructure. Exact determinations of dislocation geometries (Ardell et al., 1974) were not possible because of the rapid irradiation damage. The $g \cdot b=0$ criterion (Hirsch et al., 1967) could not be used as irradiated dislocations can not be properly brought out of image contrast. At high magnifications $(\sim 50 \mathrm{k})$ beam damage occurred after only a few seconds; at low magnifications after half a minute to a few minutes (values for $100 \mathrm{keV}$ ). 

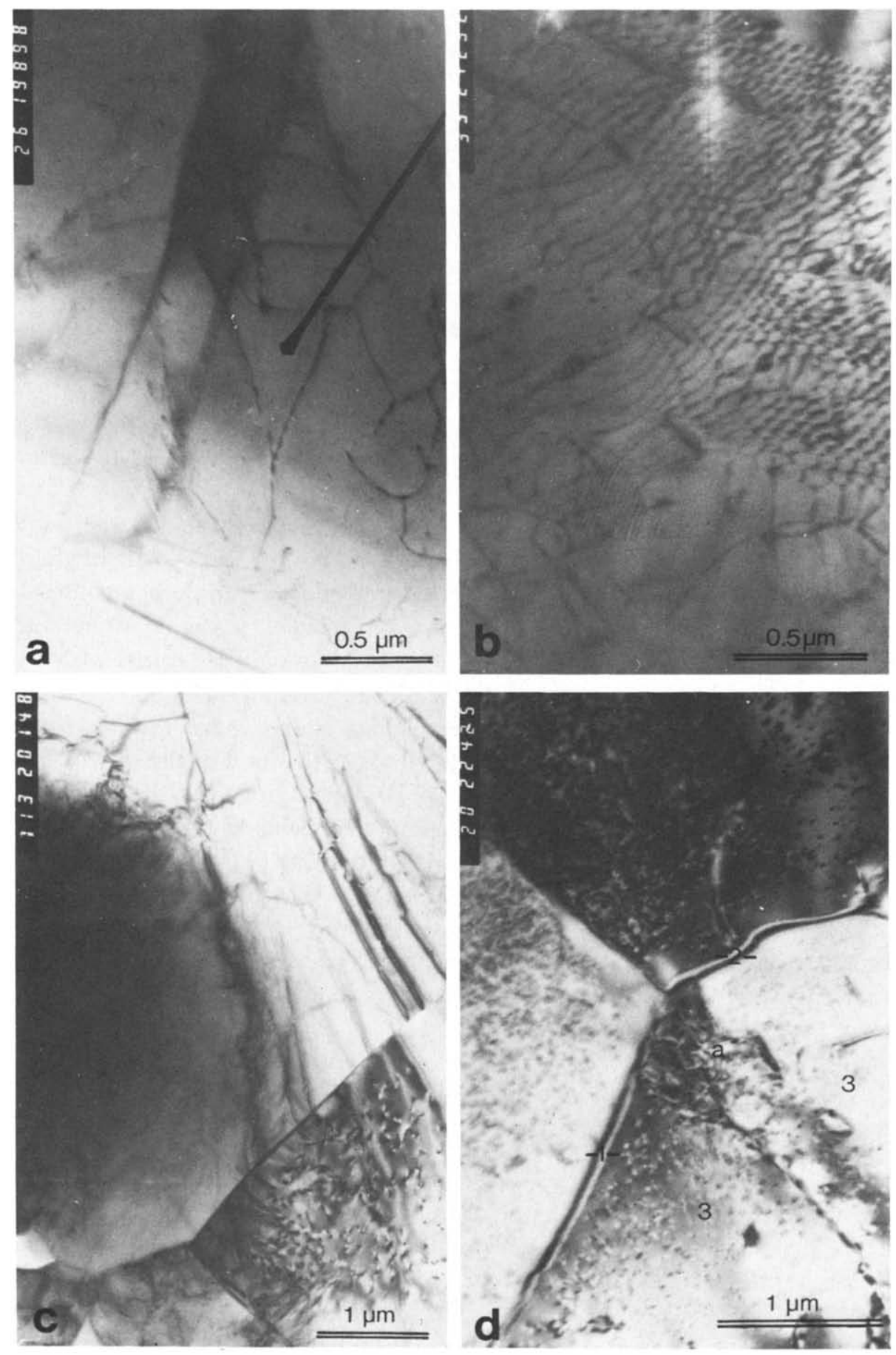

Hig. 4. a. (P1463) Dislocation images typical of a tectonite microstructure with moderate unbound dislocation density $\left(5 \times 10^{8} \mathrm{~cm}^{-2}\right)$. Long dislocation lines are generally curved and tangled. Bright field. 


\section{Tectonites}

All of the specimens examined have a high density of unbound dislocations. The average counts on up to 150 random locations in thin foil areas range from $2.4 \times 10^{8}$ $\mathrm{cm}^{-2}$ (B34) to $1.26 \times 10^{9} \mathrm{~cm}^{-2}$ (B68) (Table 1). In foils from $X Z$ thin sections unbound dislocation segments are often long, and straight or bowed (Fig. 4a) for certain tilt positions on the $Y Z$ great circle. This indicates that such sections are approximately parallel to a slip plane (Carreras et al., 1977).

Tangles and forests of interacting dislocations are often observed, especially in specimens having high unbound dislocation densities. Evidence for recovery within the crystals includes ordered arrangement of dislocations into subgrain walls (Fig. 4b) or small networks (Fig. 4a). High-angle grain boundaries are straight or slightly curved and provide very narrow image contrasts when viewed parallel to the beam direction (Fig. 4c). Curved high-angle boundaries are often subdivided into series of straight-line segments, with dislocations in the lattice of adjacent grains pinned by the corners. A $3 \times 120^{\circ}$ equilibrium at triple points is not of ten achieved, and Fig. 4d suggests that disequilibrated grain surfaces are probably maintained by gradients of internal strain energy, materialized by different dislocation densities from grain to grain.

Creep damage, i.e. arrays of elliptical voids (Ashby and Jones, 1980, p. 163) along grain boundaries or at triple junctions is not very common and generally restricted to specimens with the highest unbound dislocation densities $\left(\rho>1 \times 10^{9} \mathrm{~cm}^{-2}\right)$. Abundant spherical intracrystalline bubbles up to $2000 \AA$ in diameter occur in Pt490, B102, B59, and B60 (Table 1). They often pin dislocations in the last two specimens. Considerably smaller bubbles are associated with individual dislocations. These have been observed before in naturally (e.g., Christie and Ord, 1980) and experimentally deformed quartz (McCormick, 1977). In the latter experiments precipitation of fluids in the form of these bubbles was accompanied by hardening of the crystals.

\section{Mylonites}

The intracrystalline features in T.E.M. are nearly the same as in the tectonites. The distribution of unbound dislocations is also very heterogeneous within the

b. (B60) A subgrain wall made up by a hexagonal network of dislocations. Unbound dislocations to the left interact with the subgrain wall. Bright field.

c. (Pt463) Region of high dislocation density. Due to the different orientation of the grains families of dislocations are viewed edge-on in the lower crystal and line-on in the upper one. Bright field.

d. (C5) Triple junction of high angle qz-qz boundaries. The $3 \times 120^{\circ}$ equilibrium is disturbed by the dislocation tangle $(a)$. The dislocation density gradient causes boundaries (1) and (2) to migrate towards grain (3) in order to consume the tangle and minimize internal strain energy. The small specks are irradiation damage. Bright field. 

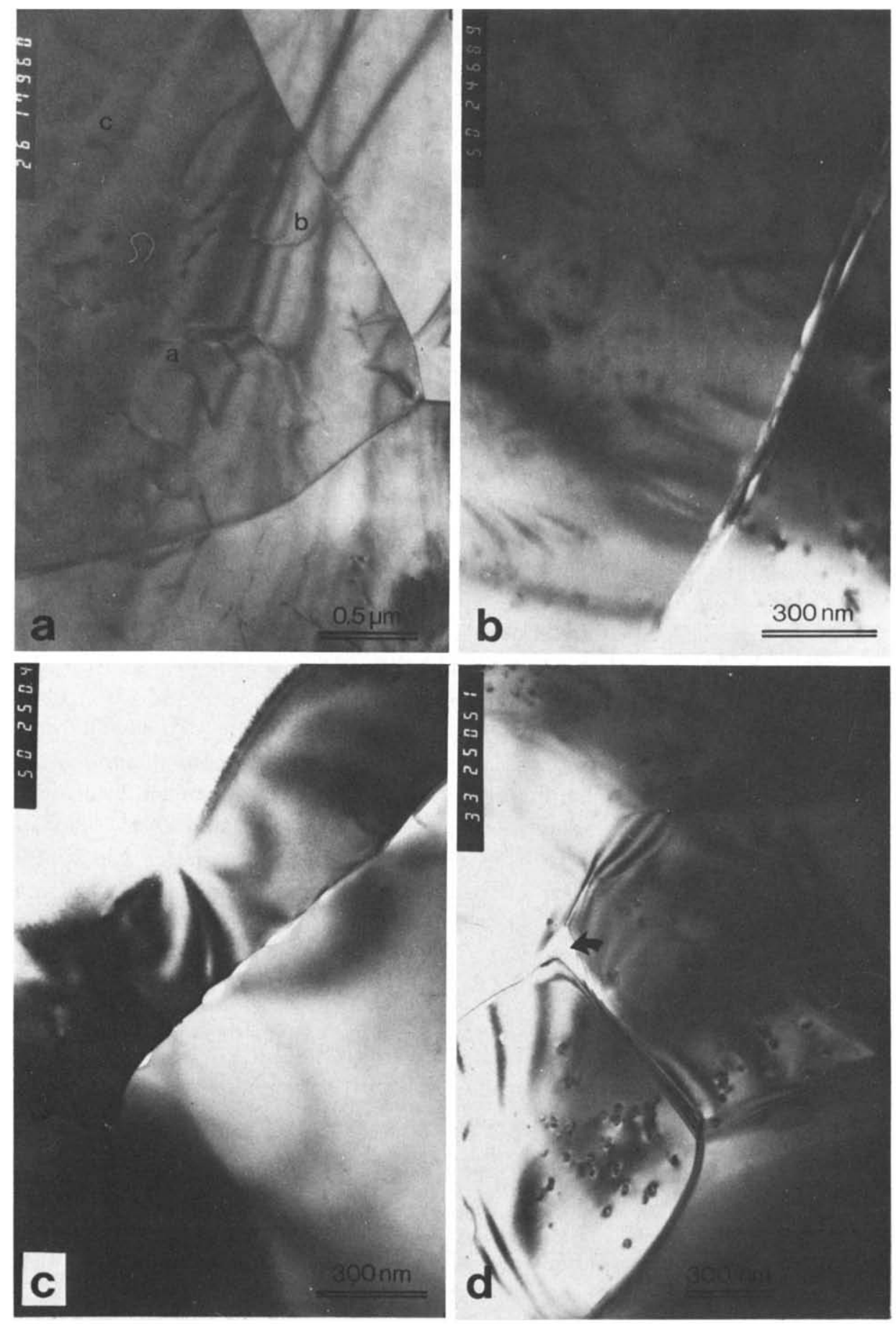
polycrystal, but there is a general association of high densities with large crystals and low densities with small ones. Average unbound dislocation densities have been determined for seven mylonites. They vary over nearly one order of magnitude from $1.6 \times 10^{8} \mathrm{~cm}^{-2}(\mathrm{C} 1)$ to $1 \times 10^{9} \mathrm{~cm}^{-2}$ (Pt 260) (see Table 1). Dislocation lines are bowed and jogged, and of ten pinned by other dislocations, grain boundaries or impurities (Fig. 5a). Recovery substructures include small interactive networks (Fig. 5 a) and ordered arrays of dislocations. Subgrain walls or tangles define cell structures within the grains with minimum cell diameters less than $1 \mu \mathrm{m}$.

The structure of grain boundaries is vastly different from those in the tectonites. Parallel to the beam direction, image contrasts are up to $1000 \mathrm{~A}$ wide (Fig. 5b). They are decorated with families of elliptical voids up to several thousand A long (Fig. 5b) suggesting creep damage in terms of Ashby and Jones (1980). Thin grain boundaries are also richly decorated with these voids (Fig. 5c). Wedge shaped (Fig. $5 \mathrm{~d}$ ) or triangular openings occur at triple junctions. In some cases their geometrical arrangement gives the impression of "en echelon" microf racturing, which could have been induced by shear along the grain boundary (Fig. 6a). Fig. 6b proves that they are not a product of preferential ion beam thinning. Whereas void (a) has been thinned open, void (b) gives a complete ellipsoidal image without being opened. Dislocations are of ten pinned by voids longer than $1000 \mathrm{~A}$. It is conceivable that they contained a fluid phase and served as nucleation loci of the dispersed second phase observed on grain boundaries and triple junctions under the optical microscope.

\section{INTERPRETATION OF MICROSTRUCTURES}

The T.E.M. observations of dislocation substructures on quartz were pioneered by McLaren and Phakey (1965). A number of later studies, done both on naturally (e.g., McLaren and Hobbs, 1972; White, 1976) and experimentally deformed quartz (Morrison-Smith et al., 1976; Ball and Glover, 1979) ascertained the importance of

Fig. 5. a. (Pt259) Typical attitude of the dislocation substructure in the mylonites: hexagonal dislocation network $(a)$. curved dislocation line pinned by grain boundaries $(b)$ or other dislocations, and small loops (c). The triple junction of high angle boundaries is near equilibrium. Bright field.

b. (B44) High angle qz-qz grain boundary in mylonite. The boundary is sub-perpendicular to the foil plane causing a $800 \mathrm{~A}$ wide image contrast. The peripheries of the boundary zone contain elliptical voids up to $1500 \mathrm{~A}$ long. Irradiation damage is incipient within the grains, but the original image of the boundary is not yet modified. Bright field.

c. (Pt488) Straight narrow high angle qz-qz grain boundary in mylonite decorated with lozenge shaped voids. The few dislocations in the neighbouring grains are viewed edge-on. Bright field.

d. (P1473) Wedge shaped triple point crack at qz-qz high angle boundaries in mylonite (arrow). The fringe patterns are caused by the obliquity of the grain boundaries with the beam direction. The small loops in the grain interiors are irradiation damage. Bright field. 
intracrystalline slip by conservative motion of dislocations as a deformational mechanism on the scale of individual mineral grains.

In the specimens described in this study, dislocations, fluid precipitates, and a large proportion of the subgrain boundaries have not achieved equilibrium configurations, i.e. straight dislocation lines, negative crystal shapes, and geometrically ordered subwalls. This largely rules out thermally activated static annealing after deformation. The optical and T.E.M. observations relate very well by comparing areas of strong undulatory extinction with dislocation tangles, and optical subgrain boundaries with ordered or non-ordered arrays of dislocations. The dislocation sub-structures reported here show striking similarities with some of the high temperature $\left(550^{\circ} \mathrm{C}\right)$ structures experimentally generated in quartz by Morrison-Smith et al. (1976).

It is interesting that these low temperature $\left(250^{\circ}-400^{\circ} \mathrm{C}\right)$ microstructures compare well with high- $T$ experiments. A qualitative explanation can be sought in the differences of strain rates between experimental and natural deformation. In steady-
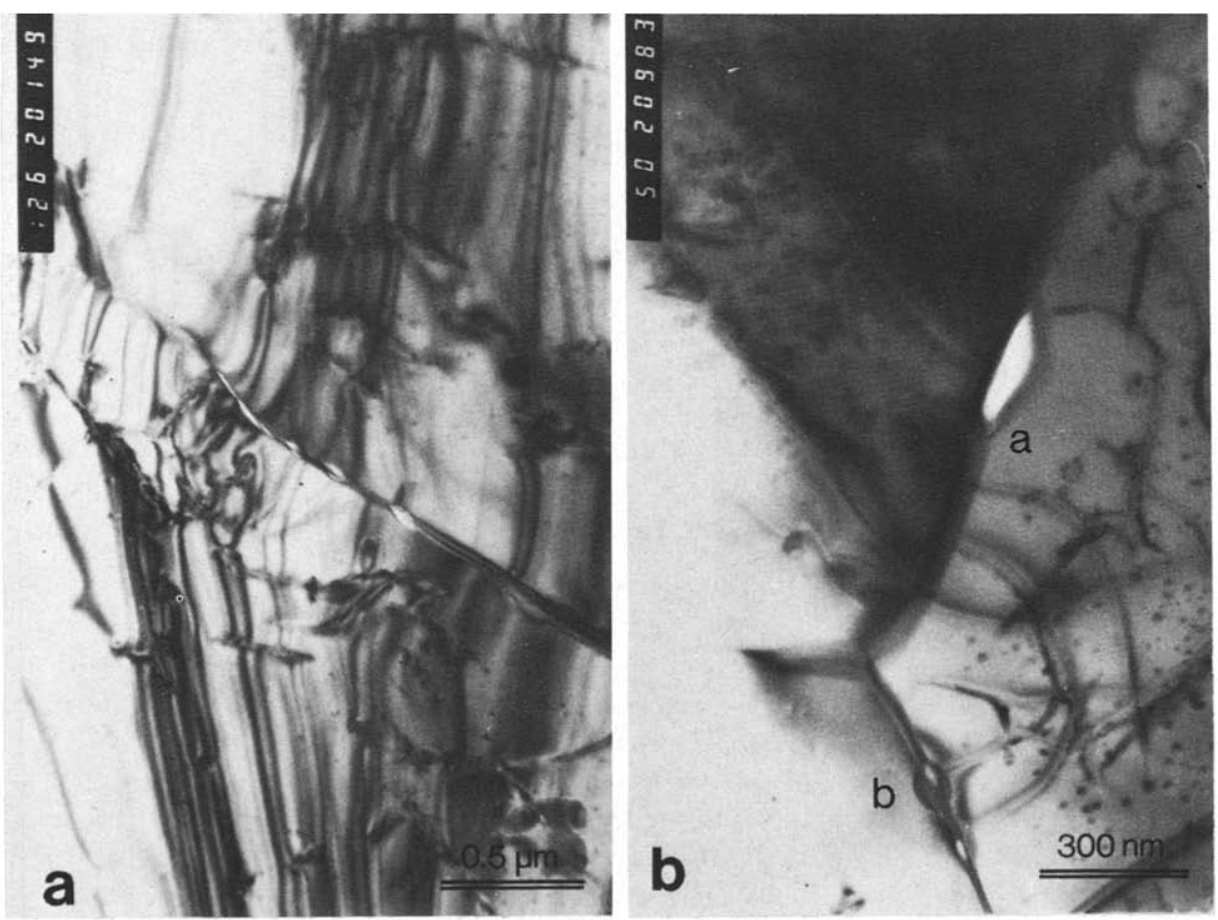

Fig. 6. a. (Pt260) En-echelon array of cracks along straight high angle boundary in quartz mylonite. Bright field.

b. (Pt488) Grain-boundary voids in quartz mylonite. Void $(a)$ is thinned open, voids $(b)$ are still completely embedded in the foil. Individual dislocations, split into partials by electron irradiation, are pinned by the voids. Bright field. 
state dislocation creep the rate of climb and recovery has to balance the rate of strain. As climb of dislocations is a thermally activated process (Weertmann, 1968). recovery at such slow natural rates may well be feasible during natural deformation of quartz at temperatures lower than $300^{\circ} \mathrm{C}$.

Without displacement markers (Mitra, 1976) there is no way to directly prove grain-boundary sliding from microstructure. The high amount of creep damage in the fine-grained mylonites, however, is comparable with phenomena in grain sliding deformation of metals with incomplete accommodation of strain incompatibilities by intracrystalline slip or diffusion (Raj and Ashby. 1975: Crossmann and Ashby. 1975). Therefore the abundance of creep damage may be taken as andication for a micromechanical situation where an essential part of the total strain in the polycrystal is produced by grain-boundary sliding. Creep damage has already been reported from a range of quartz mylonites (Christie and Ord, 1980; White and White, 1981). Zero or low creep damage in the coarser-grained tectonites suggests that grain-boundary sliding is of no or subordinate importance. Grain-boundary voids are nucleated at locations where the deviatoric stress is sufficiently large for a given confining pressure, to satisfy a fracture criterion for a quartz-quartz interface. Such sites of potential stress concentrations are steps and bumps in grain boundaries. and triple junctions.
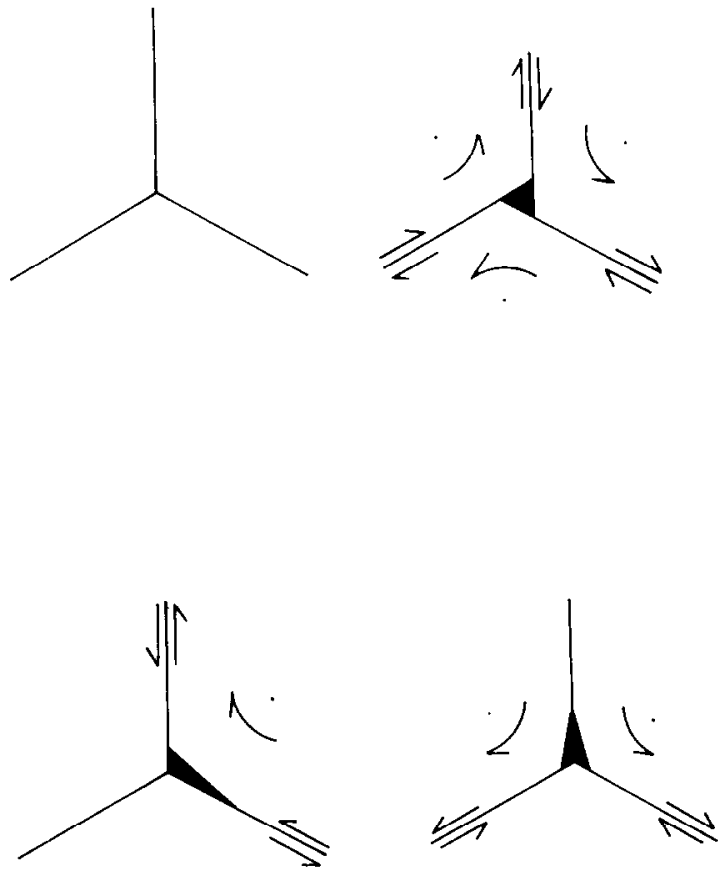

Fig. 7. Shapes of triple point cracks predicted in grain-boundary sliding for different types of combined shear along grain boundaries, induced by rigid grain rotations. 
Models for void formation at triple points are given in Fig. 7. Continuing sliding along the grain boundaries incorporates the voids into the straight boundary segments.

The dispersion of tiny second phase crystals within the mylonite specimens indicates that in contrast to the tectonites there is a certain amount of diffusional mass transfer along grain boundaries. In the case of the calcite in Pt488 (Fig. 2d) the source of the material is a calcite-dolomite mylonite layer about $20 \mathrm{~cm}$ away on top of the specimen site. Wide grain boundaries and small grain sizes favour diffusional creep (Raj and Ashby, 1971), which may provide a subsidiary accommodation mechanism for grain boundary sliding in the mylonites.

CRYSTALLOGRAPHIC PREFERRED ORIENTATION (C.P.O.)

Quartz-c-axes

$c$-axis preferred orientations in twenty deformed quartzite tectonites and mylonites have been determined by U-stage measurements. The data are presented and interpreted elsewhere (Platt and Behrmann, in press). Relevant to this study is that almost all tectonites have a distinct crossed girdle preferred orientation of type 1 (Lister and Williams, 1979) oriented broadly orthogonal to the stretching axis. This is exemplified by the point-plots of c-axes in specimen C5 (Fig. 8) where the crossed-girdle topology of the fabric is expressed by both old strained and new dynamically recrystallized grains. The degree of preferred orientation in the mylonites is much lower. The crossed-girdle topology has been partially or completely destroyed. Relict old, non-recrystallized grains in Pt488 (Fig. 8) still exhibit a rudimentary crossed girdle, but the dynamically recrystallized grains, which constitute most of the rock, have their $c$-axes oriented more or less randomly. This indicates that the large old grains probably still did deform by intracrystalline slip, whereas the dynamically recrystallized matrix adopted a different mode of deformation, probably grain-boundary sliding (see previous paragraph).

\section{$X$-ray fabrics}

The spatial intensity distribution of the diffracted beam for three reflections were measured in nine quartzite specimens: seven tectonites and two mylonites (B45 and Pt488). Reflections used are first order prisms (10 $\overline{1} 0)$, second order prisms (11 $\overline{2} 0$ ), and the combined $r$ and $z$ rhombs (1011) and (01) 1 ). A model of right handed quartz and an equal area projection of the poles to the diffracting planes used for the $\mathrm{X}$-ray texture analysis are given in Fig. 9. The relation between specimen geometry and the pole figures is shown in Fig. 1. All pole figures are equal area, lower hemisphere. 

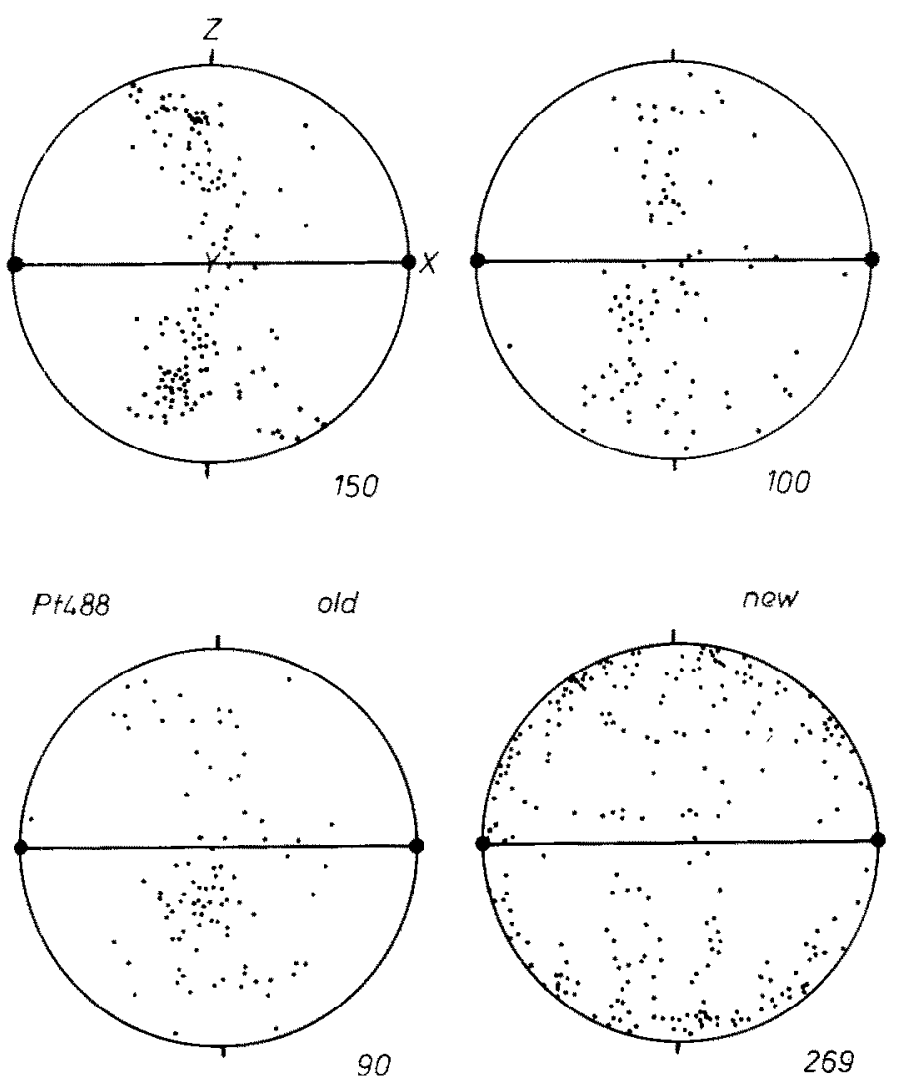

Fig. 8. Preferred orientation patterns for old and new (dynamically recrystallized) grain c-axes in $\mathrm{C} 5$ (tectonite) and Pt488 (mylonite).
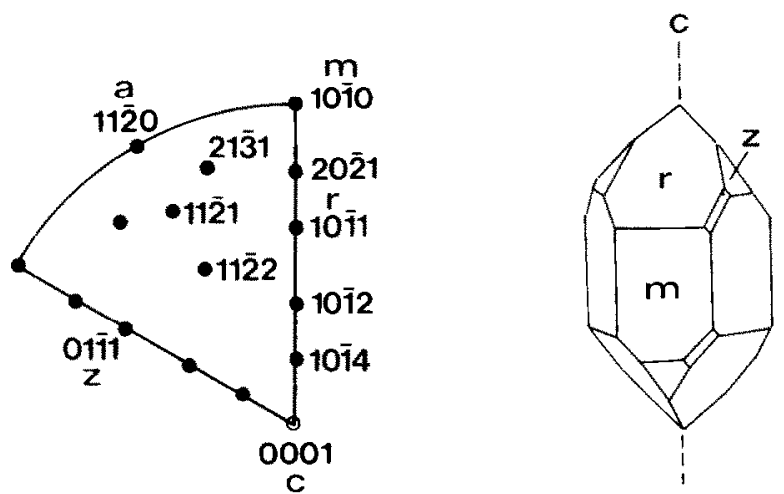

Fig. 9. Equal area projection of poles to the diffracting planes used in the X-ray texture analysis, and model of right-handed low quartz. 
The quartzite tectonites show a variably strong alignment of poles to first order prism planes parallel to the stretching lineation (Fig. 10). The strong C.P.O. in B34 may be geometrically related to an extremely strong $c$-axis orientation around $Y$ (see Platt and Behrmann, in press). In other specimens with strong $c$-axis point maxima

B5

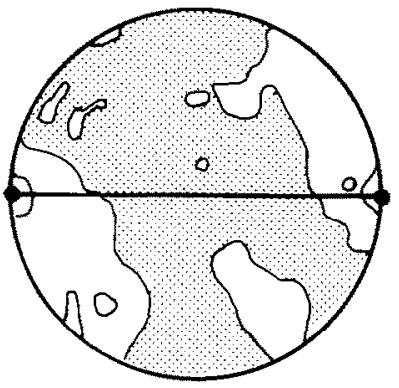

B 69

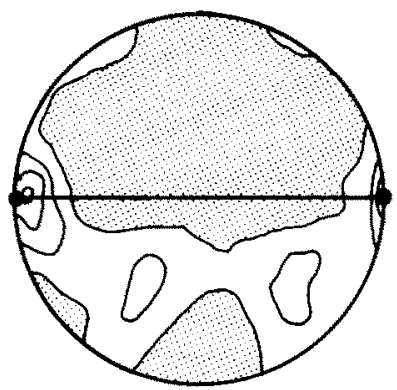

Pt 212

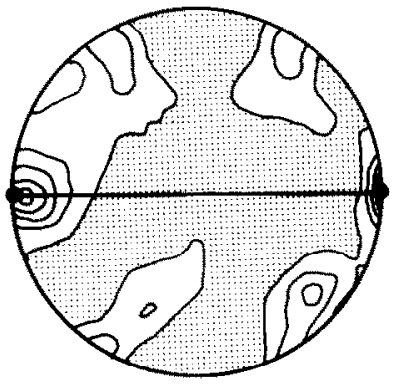

B 34

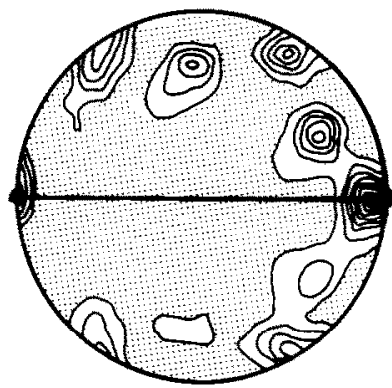

B 102

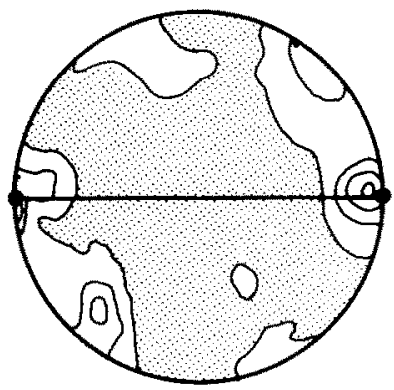

B 45

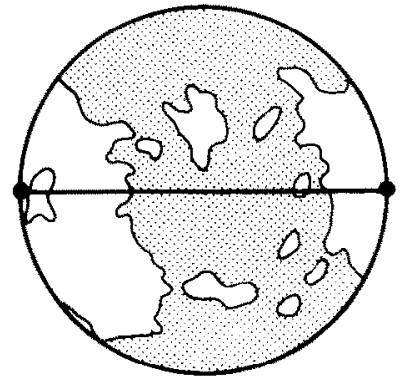

B 68

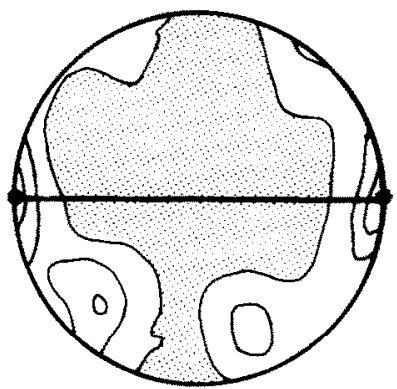

Pt 463

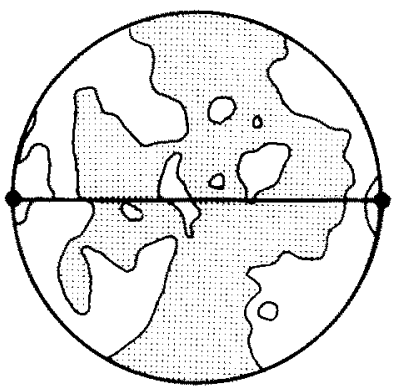

Pt 488

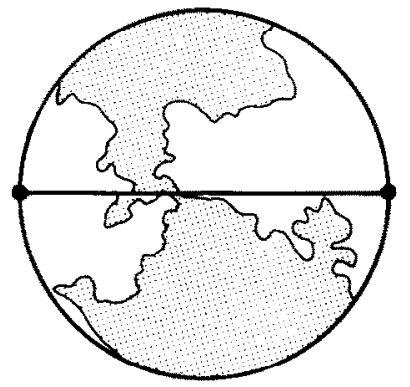

poles to $(10 \overline{10})$, lower hemisphere, equal area projection contours $1,2,3,4,5,6,7,8,9, x$ uniform $d$.

Fig. 10. Equal area, lower hemisphere projections of poles to (1010) in deformed quartz tectonites (B5, B34, B68, B69, B102, Pt 463, Pt 212) and mylonites (B45, Pt 488) from the central Sierra Alhamilla. 
on crossed girdle outlines (B68, B69) approximate single crystal textures are delineated by the (1010) pole figure as defined by the strong lineation parallel maxima and two weaker ones on great circles inclined to $X Z$. Crossed girdles with more even $c$-axis distributions along the fabric outline (Pt463, B5, Pt212) exhibit weakening of

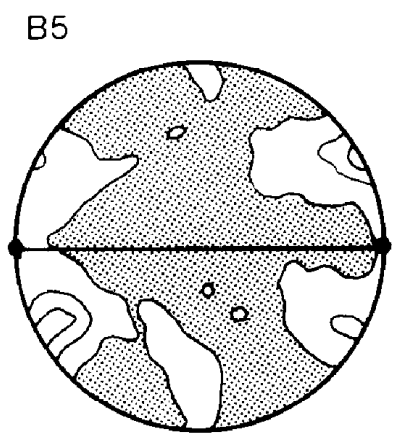

B34

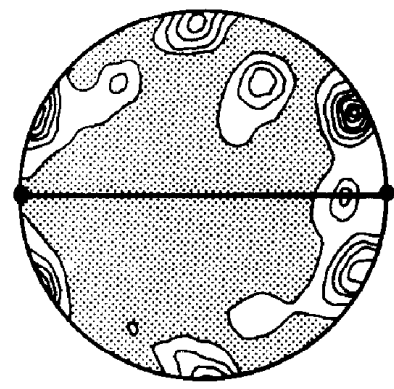

B 102

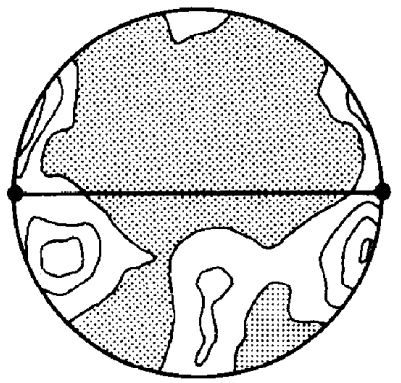

Pt 212

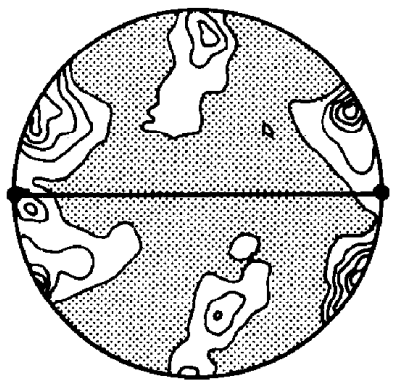

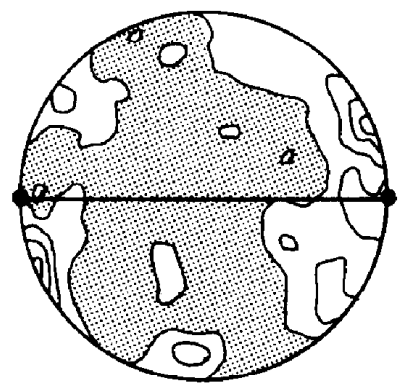

B 45

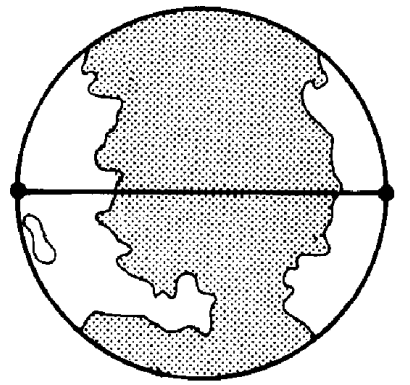

B68

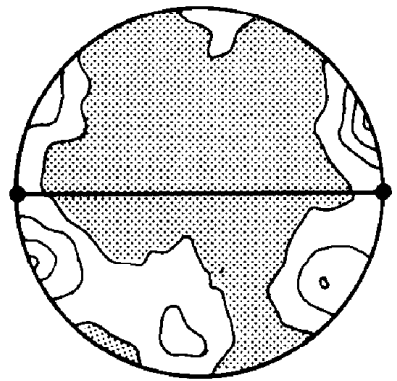

Pt 463

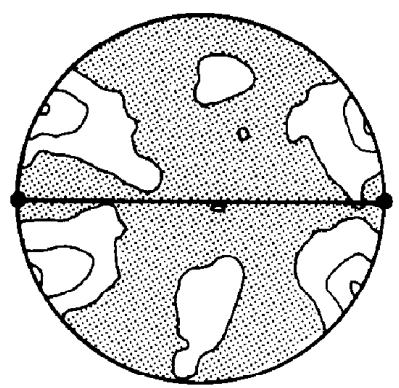

Pt 488

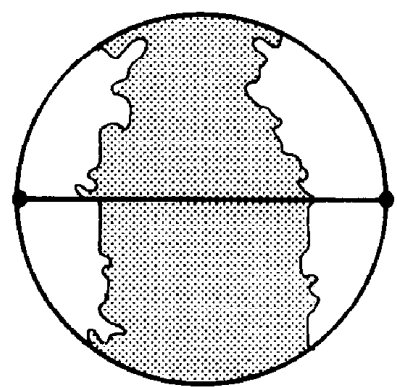

poles to $(11 \overline{2} 0)$, lower hemisphere, equal area projection contours $1,2,3,4,5,6,7, x$ uniform $d$.

Fig. 11. As Fig. 10, but projections of poles to (112̄0). 
the main (1010) maximum and strong tailing of the subordinate maxima. The (1010) preferred orientation patterns of the two mylonite specimens (Pt 488, B45) are very weak ( $2 \times$ uniform or less) with diffuse maxima around the stretching direction. This is a position broadly orthogonal to the maximum distribution of $c$-axes.

Generally the second order prism (1120) pole figures (Fig. 11) are geometrically

B5

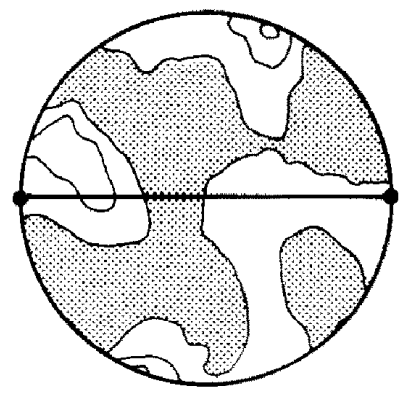

B69

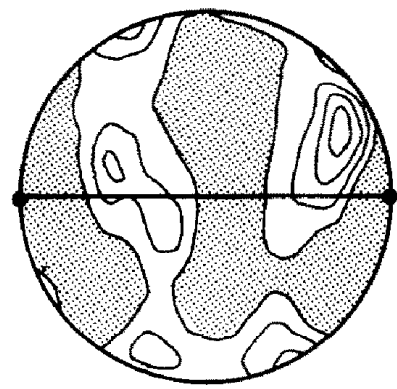

Pt 212

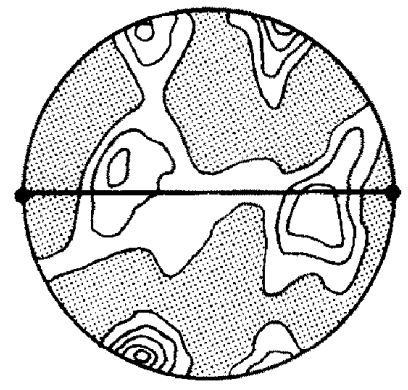

B34

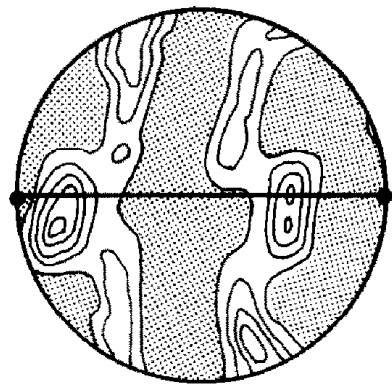

$\mathrm{B} 1 \mathrm{O} 2$

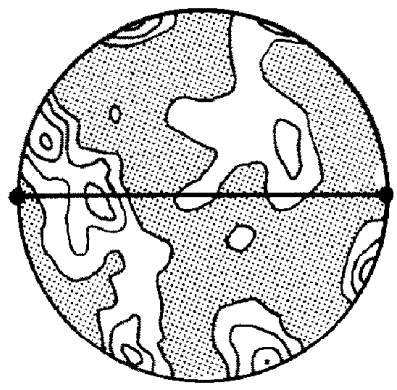

B 45

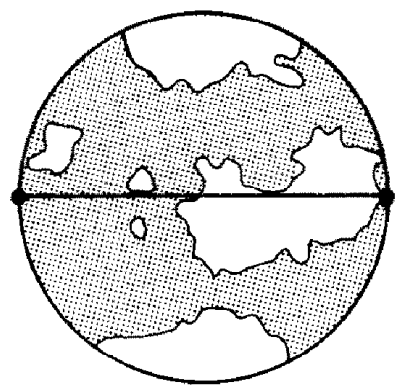

B68

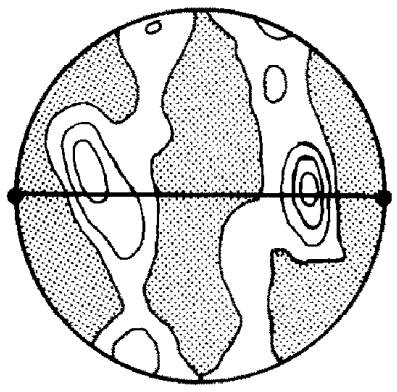

Pt 463

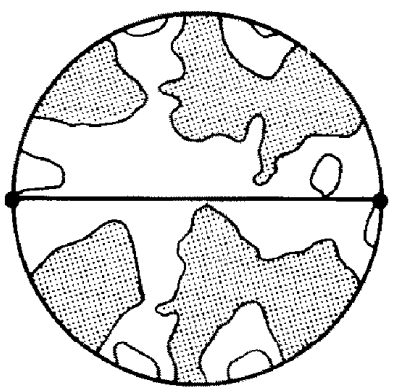

Pt 488

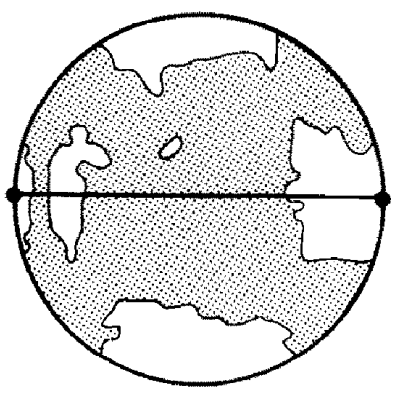

poles to (1011) and (0111), lower hemisphere, equal area projection contours $1,1.5,2,2.5,3 \times$ uniform $d$.

Fig. 12. As Fig. 10. but projections of poles to $(10 \overline{1} 1)$ and $(01 \overline{1} 1)$. 
compatible with the $(10 \overline{1} 0)$ ones. There is a very strong preferred alignment of $(11 \overline{2} 0)$ poles on the $X Z$ great circles with distinct maxima symmetrically disposed around the stretching direction $(X)$ at $30^{\circ}$ angles. The mylonites (B45, Pt488) have a very weak $(2 \times$ uniform or less) preferred orientation of $(11 \overline{2} 0)$ poles around the stretching direction.

The $r$ and $z$ rhomb preferred orientations (Fig. 12) are commonly weaker than those for the two types of prisms. The prominent topological feature in the tectonites are two girdles at intermediate angles to the stretching direction decorated with elongate maxima symmetrically disposed about $Z$, and in the vicinity of the foliation trace. The position of the two girdles is geometrically constrained by the strong preferred orientation of $c$-axes in the central part of the crossed girdle, and the preference of prism poles to line up next to the stretching direction $(X)$.

The combined rhomb fabrics in the two mylonites (B45, Pt 488) are nearly random with peak populations at any point in the pole figures less than $1.5 \times$ uniform distribution.

\section{DISCUSSION}

\section{Implications for palaeostress estimates}

Stress-dependent features in dislocation creep microstructures include: (1) the unbound dislocation density within mineral grains $(\rho),(2)$ the size of subgrains, and (3) the size of syntectonically recrystallized grains. The topic is reviewed by Nicolas and Poirier (1976), Nicolas (1978), and White (1979a). The parameters are linked to flow stress by equations which have either a theoretical or empirical basis.

Theoretically unbound dislocation density and flow stress are proportional (discussion in chapter 4 of Nicolas and Poirier, 1976).

A theory for subgrain and recrystallized grain palaeopiezometers was formulated by Twiss (1977). The stress dependence of the size of subgrains is based on the assumption that formation of sub-boundaries in crystals is an energetically favourable process being balanced by the amount of internal strain energy within the cells, or subgrains, i.e. the unbound dislocation density. Recrystallized grain size is treated in analogy to subgrain size, but allowing for a certain amount of growth once the recrystallized grain is formed. As demonstrated by Behrmann (1982) most of the new grains in the mylonites and tectonites studied have developed from subgrains by a rotation mechanism involving progressive crystallographic misorientation across sub-walls and eventual formation of high-angle grain boundaries. There are apparently two types of recrystallized grain behaviour. In the mylonites average grain size remains stable during deformation, but in the tectonites grains grow whilst being progressively deformed (see Fig. 13). The latter behaviour is in accordance with the Twiss theory. The fact that mylonite grain sizes are stable suggests that there is no dynamic balance between size and internal strain energy, and indicates that the Twiss theory cannot be extended to superplastic behaviour. 
If Twiss's (1977) reasoning is correct dislocation creep should be reflected by an inverse proportionality of unbound dislocation density and dynamically recrystallized grain size. This is indeed the case for the tectonite specimens (Fig. 14). It confirms that the tectonites deformed by dislocation creep, and given an experimental calibration both microstructural parameters could be used for palaeostress estimates.

Inferring from the microstructural observations, flow in the mylonites is probably governed by grain boundary sliding. In this flow regime the strength of a polycrystalline aggregate is reduced in proportion to its grain size (Edington et al., 1976). The finer-grained mylonites have consistently lower unbound dislocation densities than the coarser ones (Fig. 14). The generally high unbound dislocation density (Table 1) suggests, however, that intracrystalline slip is still important, probably providing the major intragranular accommodating mechanism for grain boundary sliding. Hence, diminishing $\rho$ can be interpreted to reflect a reduction in flow strength as grain sizes are reduced, and may be used to estimate flow stress levels.
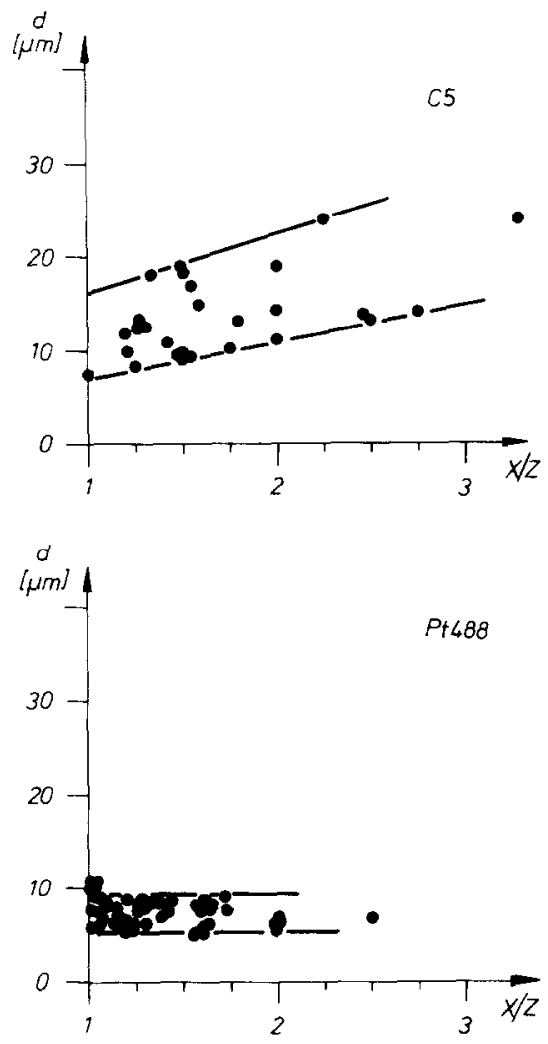

Fig. 13. Dynamically recrystallized grain sizes as a function of new grain $X / Z$ aspect ratio in $\mathrm{C} 5$ (tectonite) and Pt488 (mylonite). For explanation see text. 
How does nature manufacture such fine-grained mylonites? If the grain-size reduction process (dynamic recrystallization) inferred from the microstructural observations is active, a high initial level of flow stress in the dislocation creep regime is required to produce aggregates finer than $10 \mu \mathrm{m}$, which seems to be the critical upper grain size to activate grain size sensitive creep by boundary sliding (see Fig. 14). Such sufficiently high initial stresses may be generated at the propagating tips of ductile shear zones within stressed bodies of rock (as proposed by Cobbold, 1977; White, 1979b). It is suggested that such a shift in deformation mechanisms gives the Fuentes and Cuillas mylonites in the Sierra Alhamilla their status as highstrain/high-displacement zones, or "superactive" shear zones within a much larger belt of bulk intracrustal shearing (the Betic Movement Zone). Superplasticity would lead to an acceleration in strain rates if the flow stress is maintained. The fine recrystallized grain size can then be interpreted as the memory of the initial high flow-stress level at which the mylonites where formed. As discussed above, the

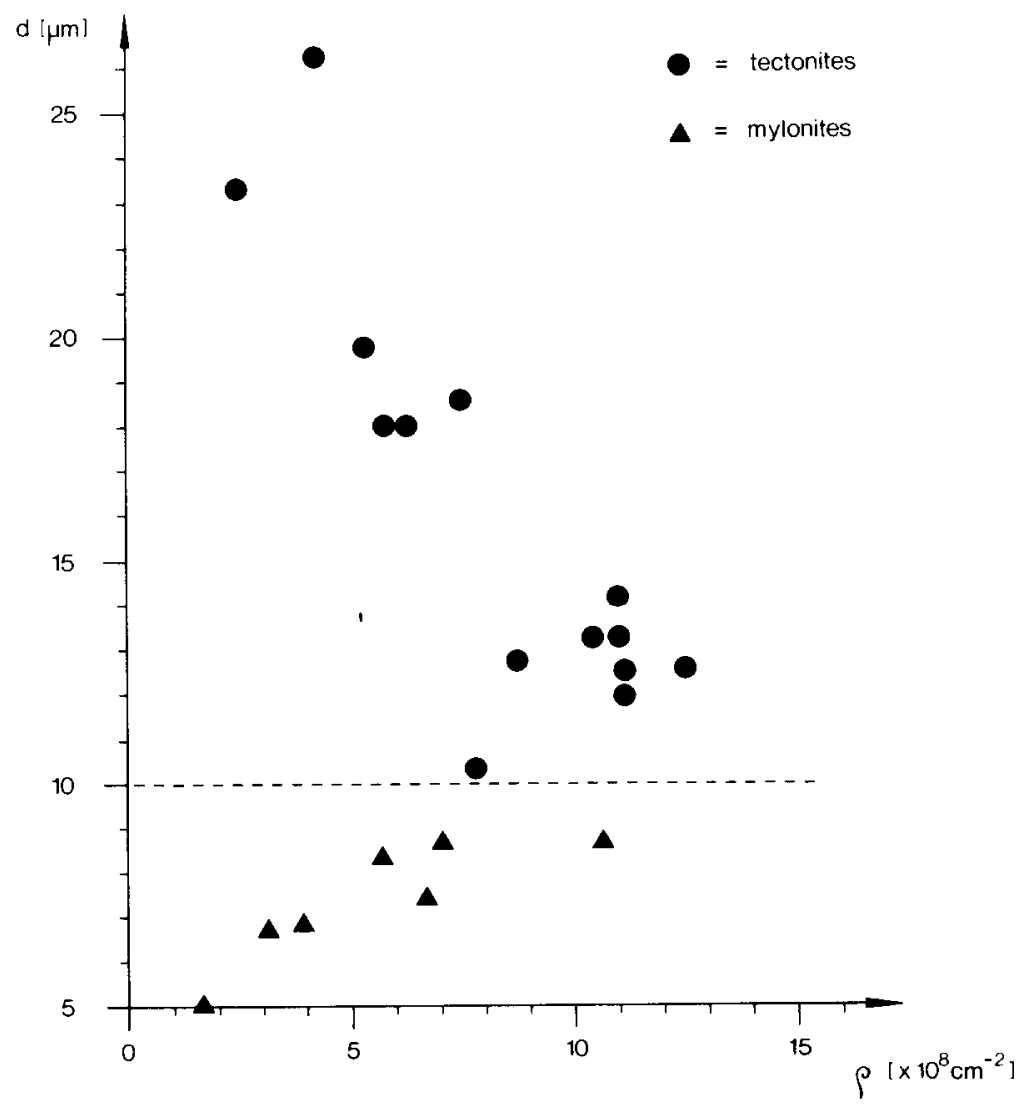

Fig. 14. The correlation between dynamically recrystallized grain size $(d)$ and unbound dislocation density $(\rho)$ in the tectonite and mylonite specimens. For discussion see text. 
proportionality between grain size and free dislocation density in the mylonites (Fig. 14) may at least be a reflection of late stage flow stresses.

\section{Work softening}

Deformation tends to be heterogeneous, no matter which hierarchy of scales is chosen. The causes are either intrinsic mechanical or thermal heterogeneities or those created during deformation of a previously homogeneous portion of crust. The latter phenomenon is well known as work hardening or work softening in metallurgy and materials science, and has been advocated to explain initiation and flow localization in shear zones (e.g. Cobbold, 1977; Poirier, 1980; White et al., 1980). Work softening mechanisms include changes in microstructure of a single phase (Sellars, 1978), or two-phase systems (Le Hazif, 1978). The preferred alignment of active slip systems into easy glide orientation with respect to the kinematic reference frame is reported to soften single crystals significantly (Boas and Schmid, 1929). For polycrystalline materials this "geometrical softening" phenomenon is only likely to be important

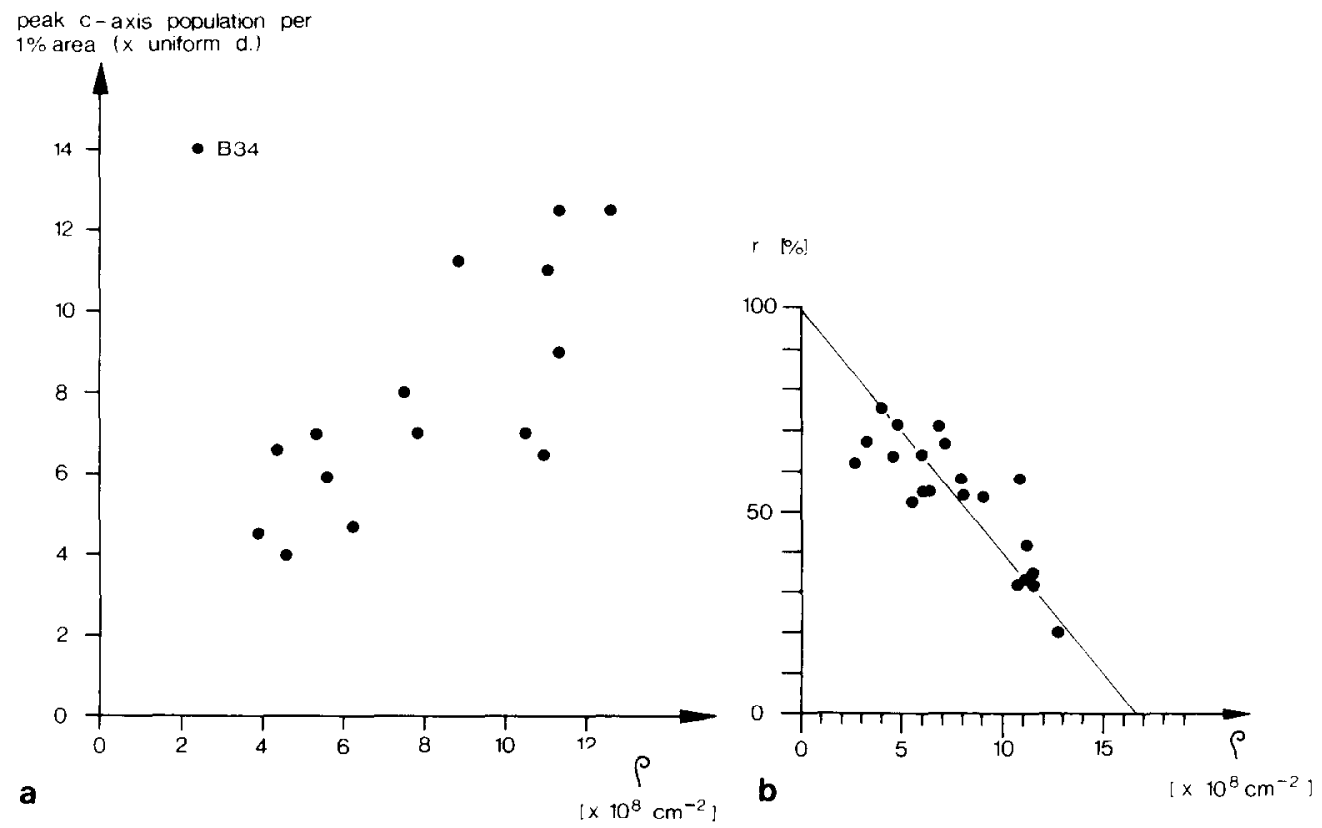

Fig. 15. a. Unbound dislocation density $(\rho)$, possibly reflecting polycrystal strength as a function of the degree of crystallographic preferred orientation (represented by the peak population of c-axes per $1 \%$ area) in the central Sierra Alhamilla quartzites.

b. Unbound dislocation density as a function of the percentage of dynamic recrystallization $(p)$ in the central Sierra Alhamilla quartzites. Linear regression on the data yields a softening function $\rho=1.68 \times 10^{-7}$ $r+1.639 \times 10^{9}$. The correlation coefficient is 0.83 . 
until a stable crystallographic preferred orientation (C.P.O.) pattern is achieved. i.e. in the early stages of deformation (see discussion in Poirier, 1980). Other possible effects, which are not subject to investigation here. like shear heating, reaction softening, or chemical softening are reviewed by White et al. (1980).

The data determined from our specimens are suitable to inquire about: (1) the relation between the degree of C.P.O. and the flow strength of quartz polycrystals. and (2) the effect of dymamic recrystallization on flow strength.

In the previous paragraph I have argued that the unbound dislocation density $(\rho)$ is probably a suitable measure of steady. or late stage flow strength of both tectonites and mylonites. If those polycrystals showing the best defined C.P.O. patterns for easy slip are to be the softenest ones. they should bear the lowest unbound dislocation densities. Figure 15a shows that rather the opposite is the case. Specimens with high $\rho$ normally exhibit a strong C.P.O., here indicated by the peak population of $c$-axis orientations in a $1 \%$ area of the fabric diagram (data from Behrmann, 1982). Specimen B34 is a notable exception, which may be due to the approximate double maximum orientation for easy slip on $(1010)\langle a\rangle$ (see Figs. 10 and 11). This is probably the only true example for geometrical softening within the range of specimens.

The effect of microstructural change from a coarse $(>200 \mu \mathrm{m})$ to a bimodal, but preferentially fine grained assemblage can be investigated by relating the percentage of dynamic recrystallization to the unbound dislocation density $(\rho)$ (Fig. 15b). Recrystallization percentages are corrected for pure quartzite (Table 1). There is clearly an inverse proportionality of the amount of dynamic recrystallization and $\rho$. This means that polycrystal softening is critically dependent on the ability of the material to recover and recrystallize to finer grain sizes.

Unavoidably there are errors in this relationship, strikingly demonstrated by the intersection of the graph with the $y$-axis at $r<100 \%$. This would mean less than zero flow strength for a completely recrystallized aggregate. Probably the main sources of error are the so far unknown effects of the second phase admixture on ductility. Also the softening effect potentially arising from the reduction of cohesive strength of quartz-quartz grain boundaries in the mylonites (see paragraph on T.E.M. microstructure) is not accounted for. It should be mentioned that such quantifications of work softening are strictly valid only for suites of isothermally deformed rocks, and should not be extrapolated to deformation in different metamorphic grades and environments. The model and softening function proposed here may provide a valid generalization for the microstructural softening of quartz in the temperature range of lower greenschist facies.

Judging from the amount of dynamic recrystallization and the slope of the graph in Fig. 15 b, both tectonites and mylonites may well have lost between $20 \%$ and $70 \%$ of their original (pre-recrystallization) flow strength. If this behaviour of quartzite is in any way representative for the mechanical behaviour of the ductile regions within the quartzo-feldspathic crust, the possibility has to be considered that the stresses 
needed to detach nappes, initiate strike slip shearing etc. within the earth's crust may be significantly higher than those estimated from microstructures within shear zones that have operated and softened.

\section{CONCLUSIONS}

(1) The microstructures of the quartzite tectonite and mylonite specimens studied, developed by syntectonic recrystallization of originally coarse grained aggregates. Deformation in the tectonites was probably achieved by dislocation creep with the climb capability of dislocations providing the rate controlling step. Flow in the two mylonite carpets may have been superplastic after formation of the very fine grained $(<10 \mu \mathrm{m})$ microstructure. The breakdown of the C.P.O. serves as additional evidence for this. Grain boundary sliding was probably accommodated by dislocation processes within the crystallites. A recrystallized grain size of less than $10 \mu \mathrm{m}$ is seen to be critical for the switch from dislocation creep to superplasticity. This is explicitly demonstrated in Fig. 14 by the complete reversal of proportionality between dynamically recrystallized grain size and unbound dislocation density.

(2) Dynamically recrystallized grain size and unbound dislocation density are useful palaeostress indicators in those specimens that bear microstructural and fabric memories of dislocation creep. Unbound dislocation densities are subject to easy adjustment as they can be readily modified by static annealing or late stage influences on deformation histories. However, the general absence of equilibrium microstructures largely rules out annealing, and interaction of more stable subgrain walls and free dislocations suggests a causal relationship between the two. The fine grain size in the mylonites is interpreted as a remainder of high initial stresses that allowed dynamic recrystallization to grain sizes smaller than $10 \mu \mathrm{m}$. Unbound dislocation densities possibly relate to late stage flow stresses in the mylonites.

(3) The flow strength of the quartzites studied is critically dependent on the amount of dynamic recrystallization. This suggests that microstructural transformation to finer grained aggregates is an important mechanism for softening of quartz in ductile shear zones. Palaeostress values extracted from microstructures in shear zones may therefore be substantially lower than those needed to initiate ductile shearing in quartz-rich crustal materials.

(4) Work softening by dynamic recrystallization and the deformation mechanism switch from dislocation creep to superplasticity are two independent phenomena, although they may interact in localizing flow within the earth's crust. Large increases in strain rate, and hence in finite strain seem to be confined to rocks that achieve the transition from dislocation creep to superplasticity. This is demonstrated by the fact that microstructures and textures indicating superplastic flow are confined to the high strain mylonite belts in the studied area. 


\section{ACKNOWLEDGEMENTS}

T.E.M. facilities were provided by the Departments of Crystal Chemistry and Metallurgy, University of Oxford. X-ray fabrics were measured at Geologisches Institut, E.T.H. Zürich. I wish to thank José Seguro Nieto and S.M. Schmid for their kind hospitality. J.P. Platt contributed to the specimens used in this study. I am grateful to M. Casey, D. Evans, G. Lister, M. Norton, J. Platt, E. Rutter, S.M. Schmid, H. Stel and R. Vissers for discussions on the deformational behaviour of quartz. The late R. Holland, and P. Jackson, W. Wetzel and H. Wörner are thanked for technical and secretarial assistance. This study was carried out during the tenure of a Florey European Studentship at The Queen's College, Oxford.

\section{REFERENCES}

Ardell, AJ., Christie, J.M. and Tullis, J.A., 1974. Dislocation substructures in deformed quartz rocks. Cryst. Lattice Defects, 4: 27S-285.

Ashby, M.F. and Jones, D.R.H., 1980. Engineering Materials. Pergamon, London, 278 pp.

Ashby, M.F. and Verall, R.A., 1973. Diffusion accomodated flow and superplasticity. Acta Metall., 21 : $149-163$

Avé Lallemant, H.G. and Carter, N.L., 1971. Pressure dependence of quartz deformation lamellae orientations. Am. J. Sci., 270: 218-235.

Baker, D.W., Wenk. H.R. and Christie, J.J., 1969. X-ray analysis of preferred orientation in fine-grained quartz-aggregates. J. Geol., 77; 140-171.

Ball, A. and Glover, G., 1979. Dislocation climb deformation in quartz. Bull. Mineral., 102: $188-194$.

Barber, D.J., 1970. Thin foils of non-metals made for electron microscopy by sputter etching. J. Mater. Sei., $5: 1-8$.

Behrmann, J.H. 1982. Structures and deformational processes in a zone of contact strain beneath a nappe, Sierra Alhamilla, Spain. D. Phil. Thesis, Oxford, $290 \mathrm{pp}$.

Behrmann, J.H., 1984. Patterns of palaeostress and strain beneath the Aguilon nappe, Betic Cordilleras. Spain. Z. Dtsch. Geol. Ges., 135: 293-305.

Behrmann, J.H. and Platt, J.P., 1982. Sense of nappe emplacement from quartz $c$-axis fabrics; an example from the Betic Cordilleras (Spain). Earth Planet Sci. Lett., 59; 208-215.

Boas, W. and Schmid, E., 1929. Uber die Dehnung von Cadmiumkristallen. Z. Phys., 54: 16-34.

Bouchez, J.L., 1978. Preferred orientations of quartz $\langle a\rangle$ axes in some tectonites: kinematic inferences. Tectonophysics, 49: T25-T30.

Bouchez, J.L., Lister, G.S. and Nicolas, A., 1983. Fabric asymmetry and shear sense in movement zones. Geol. Rundsch., 72: $401-419$.

Boullier, A.M. and Gueguen, Y.. 1975. SP-mylonites. Origin of some mylonites by superplastic flow. Contrib. Mineral. Petrol. 50: 93-105.

Carreras, J., Estrada. A. and White, S.H., 1977. The effect of folding on the $c$-axis fabrics of a quartz mylonite. In: G.S. Lister, P.F. Williams, H.J. Zwart and R.I I.isle (Fditor), Fabrics, Microstructures and Microtectonics. Tectonophysics, 39: 3-24.

Cherns. D., Jenkins, M.L. and White, S., 1980. The structure of dislocations in quartz under electron irradiation. Inst Phys. Conf Ser., 52: 121-124.

Cobbold, P.R., 1977. Description and origin of banded deformation structures II. Rheology and growth of banded perturbations. Can. J. Earth Sci., 14: 2510-2532.

Christie, J.M. and Ord, A., 1980. Flow stress from microstructures of mylonites: example and current assessment. J. Geophys. Res., 85: 6253-6262. 
Crossmann. F.W. and Ashby, M.F.. 1975. The non-uniform flow of polycrystals by grain-boundary sliding accommodated by power law creep. Acta Metall. 23: 425-440.

Durney. D.W. 1972. Solution transfer, an important geologic deformation mechanism. Nature. 235: $315-317$.

Edington, J.W. Melton, K.N. and Cutler. C.P., 1976. Superplasticity. Progr. Mater. Sci., 21: 63170.

Egeler. C.G. and Simon. O.J., 1969. Sur la tectonique de la zone Bétique (Cordillères Bétiques, Espagne). K. Ned. Akad. Wet. Verh.. 25: 90 pp.

Etheridge. M.A. and Wilkic. J.C.. 1979. Grainsize reduction. grain boundary sliding and the flow strength of mylonites. In: T.H. Bell and R.H. Vernon (Editors). Microstructural Processes during Deformation and Metamorphism. Tectonophysics, 58: 159-178.

Gray. D.R., 1979. Microstructure of crenulation cleavages: an indicator of cleavage origin. Am. J. Sci.. 279: 97-128.

Ham. R.K.. 1961. The determination of dislocation densities in thin films. Philos. Mag. 6: 1183-1184.

Ham. R.K. and Sharpe. N.G. 1961. A systematic error in the determination of dislocation densities in thin films. Philos. Mag. 6: 1193-1194.

Hirsch, P., Howie. A., Nicholson. R.B.. Pashley, D.W. and Whelan, M.A.. 1967. Electron Microscopy of Thin Crystals. Butterworths, London, $563 \mathrm{pp}$.

LeHazif. R., 1978. Déformation plastique du système biphasé Fér-Argent de composition equivolumique. Acta. Metall., 26: 247-257.

Lister, G.S. and Williams. P.F.. 1979. Fabric development in shear zones: theoretical controls and observed phenomena. J. Struct. Geol.. 1: 283-297.

Lister. G.S., Paterson. M.S. and Hobbs. B.E., 1978. The simulation of fabric development in plastic deformation, and its application to quartzite: the model. Tectonophysics. 45: 107-158.

McCormick, I.W.. 1977. Transmission electron microscopy of experimentally deformed synthetic quartz. Ph.D. Thesis. UCLA, $171 \mathrm{pp}$.

McLaren. A.C. and Hobbs, B.E.. 1972. Transmission electron microscope investigations of some naturally deformed quartzites. In: Flow and Fracture of Rocks, the Griggs Vol. 16. Am. Geophys. Union. Byrd W. Press. pp. 55-66.

McLaren. A.C. and Phakey, P.P., 1965. Dislocations observed in quartz by transmission electron microscopy. J. Appl. Phys.. 36: 3244-3246.

Mitra. S.. 1976. A quantitative study of deformation mechanisms and finite strain in quartzites. Contrib. Mineral. Petrol., 59: 203-226.

Morrison-Smith. D.J., Paterson. M.S. and Hobbs. B.E. 1976. An electron microscope study of plastic deformation in single crystals of synthetic quartz. Tectonophysics. 33:43-79.

Nicolas, A.. 1978. Stress estimates from structural studies in some mantle peridotites. Philos. Trans. R. Soc. London. Ser. A. 288: 49-57.

Nicolas. A. and Poirier, J.P., 1976. Crystalline plasticity and solid state flow in metamorphic rocks. Wiley-Interscience. New York, N.Y.. $462 \mathrm{pp}$.

Platt, J.P., 1982. Emplacement of a fold-nappe, Betic orogen, southern Spain, Geology, 10: 97-102.

Platt, J.P. and Bchrmann. J.H., 1985. The Betic Movement Zone: a major intracrustal shear zone in the Sierra Alhamilla, SE Spain. J. Struct. Geol., in press.

Platt, J.P. and Vissers. R.L.M., 1980. Extensional structures in anisotropic rocks. J. Struct. Geol.. 2: $397-410$.

Platt. J.P.. Behrmann. J.H., Martinez, J..M.M. and Vissers, R.L.M., 1984. A zone of mylonite and related ductile deformation beneath the Alpujarride nappe complex. Betic Cordilleras. S. Spain. Geol. Rundsch.. 73: 773-785.

Poirier, J.P., 1980. Shear localization and shear instability in materials in the ductile field. J. Struct. Geol. 2: $135-142$

Raj. R. and Ashby, M.F., 1971. On grain boundary sliding and diffusional ereep. Metall. Trans., 2: $1113-1127$. 
Raj, R. and Ashby, M.F., 1975. Intergranular fracture at elevated temperature. Acta. Metall. 23: $653-666$

Rutter, E.H., 1976. The kinetics of rock deformation by pressure solution. Philos. Trans. R. Soc. London. Ser. A. 283: 203-219.

Schrnid, S.M. Casey. M. and Starkey, J.. 1981a. The microfabric of calcite tectonites from the Ilelvetic Nappes (Swiss Alps). In: McClay, K.R. and Price. N.J. (Editor). Thrust and Nappe Tectonics. Geol. Soc. London, Spec. Publ., 9: 151-158.

Schmid. S.M. Casey. M. and Starkey, J., 1981b. An illustration of the advantages of a complete texture analysis described by the orientation distribution function (ODF) using quartz pole figure data. Tectonophysics. 78: 101-118.

Schmidt. W. 1925. Gefügestatistik. Mineral. Petrol. Mitt. 38: 392.

Sellars. C.M. 1978. Recrystallization of metals during hot deformation. Philos. Trans. R. Soc.. 135: $513-516$.

Siddans. A.W.B. 1976. Deformed rocks and their textures. Philos. Trans, R. Soc. London. Ser. A. 283: 43-54.

Torres-Roldan, R.L. 1979. The tectonic subdivision of the Betic zone (Betic Cordilleras, southern Spain): its significance and one possible geotectonic scenario for the westernmost alpine belt. Am. J. Sci. 279: $19-52$.

Tulis. J., Christie, J.M. and Griggs, D.T., 1973. Microstructures and preferred orientations of experimentally deformed quartzites. Geol. Soc. Am. Bull., 84: 297-314.

Twiss. R.J., 1977. Theory and applicability of a recrystallized grain size paleopiezometer. Pure Appl. Geophys.. 115: 227-244.

Vissers, R.L.M., 1981. A structural study of the central Sierra de los Filabres (Betic Zone. SE Spain). with emphasis on deformational processes and their relation to the Alpine metamorphism. Ph.D. Thesis. Amsterdam, $154 \mathrm{pp}$.

Weertman, J., 1968. Dislocation climb theory of steady state creep. Trans. ASME. 61: 681-694.

White. J.C. and White, S.H. 1981. On the structure of grain boundaries in tectonites. Tectonophysics. 78 : $613-628$

White. S. 1973. Syntectonic recrystallization and texture development in quartz. Nature. 244: 276-278.

White. S.. 1976. The effects of strain on the microstructures, and fabrics and deformation mechanisms in quartzites. Philos. Trans. R. Soc. London. Ser. A, 283: 6986.

White. S.H.. 1979a. Difficulties associated with paleo-stress estimates. Bull. Mineral., 102: 210-215.

White, S.H., 1979b. Grain and subgrain size variation across a mylonite zone. Contrib. Mineral. Petrol.. 70: 1933-202.

White, S.H., Burrows, S.E. Carreras. J., Shaw. N.D. and Humphreys, F.J.. 1980. On mylonites in ductile shear zones. J. Struct. Geol.. 2: 175-187. 